\title{
¿Ángel 0 demonio? Los efectos del comercio chino en los países de América Latina
}

\author{
Jorge Blázquez-Lidoy, Javier Rodríguez y Javier Santiso
}

Jorge Blázquez-Lidoy

Oficina Económica del Presidente,

España

• blázquezlidoy@ telefónica.net

Javier Rodríguez

Economista, Departamento

de Mercados Globales,

Banco Bilbao Vizcaya Argentaria (BBVA)

• javier.rgarcia@grupobbva.com

Javier Santiso

Economista Jefe y Director Adjunto,

Centro de Desarrollo,

Organización de Cooperación

y Desarrollo Económicos (OCDE)

$\infty$ javier.santiso@oecd.org a economía china ha crecido a pasos agigantados y es hoy actor importante del comercio mundial. Para América Latina, el crecimiento chino constituye a la vez una amenaza y una oportunidad. En general, y pese a algunas excepciones, la integración de China al comercio mundial favorece claramente a América Latina. Para analizar los efectos del auge comercial chino, se estudió la estructura exportadora e importadora del país. Utilizando una base de datos que abarca 620 productos, se establecieron dos índices de competitividad comercial para comparar los efectos del comercio chino en 34 economías, 15 de ellas latinoamericanas, en el período 1998-2004. A grandes rasgos, los resultados confirman que en el mercado estadounidense no existe demasiada competencia comercial entre China y América Latina. Obviamente, el grado de competencia es menor en el caso de los países que exportan principalmente productos básicos (commodities), dado que China es importador neto de materias primas y América Latina tiene una abundante dotación de ellas. 


\section{Introducción}

En los últimos dos decenios, China se ha convertido en un actor económico importante a nivel mundial. Según datos oficiales, en menos de 20 años la tasa de crecimiento del PIB se ha elevado a la extraordinaria cifra de casi $9,5 \%{ }^{1}$ y su participación en el comercio mundial ha avanzado de un mero $1 \%$ a más de $6 \%$.

La integración de China en la economía mundial figura ya como uno de los hitos más importantes de las últimas décadas. En el año 2003, ocupó el sexto lugar entre las principales economías del mundo al tipo de

$\square$ Este trabajo fue presentado en el año 2004 en el Centre for Latin American Studies de la Universidad de Georgetown; el Institute for Latin American Studies de la Universidad de Columbia; la conferencia "Asia and Latin America: Opportunities and Challenges - The World Bank Ninth LAC Meets the Market Conference" (Banco Mundial y Deutsche Bank, Nueva York); el Noveno Encuentro Anual de la Asociación de Economía de América Latina y el Caribe (San José de Costa Rica) y la Corporación Andina de Fomento (Caracas). En el 2005 fue presentado en el Centro de Desarrollo de la Organización para la Cooperación y el Desarrollo Económicos (París); la Reunión Anual de la Junta de Gobernadores del Banco Interamericano de Desarrollo, seminario oficial "América Latina y Asia en la economía mundial: hacia el fortalecimiento de los vínculos y la cooperación interregionales en el ámbito económico" (Okinawa), y la Conferencia Anual del Banco Mundial sobre Economía del Desarrollo-Europa (Ámsterdam). Por último, en el año 2006 se presentó en la Conferencia Anual del Banco Mundial sobre Economía del Desarrollo-Europa (Tokio). Los autores agradecen a Santiago Sanz, Juan Antonio Rodríguez y Luciana Taft su apoyo técnico y sus valiosos comentarios. También agradecen a José María Álvarez Pallete, Claustre Bajona, Jean Christophe Bas, Dominique Bocquet, Guillermo Calvo, Eliana Cardoso, Luis Miguel Castilla, Carlos Elizondo, Barry Eichengreen, Antoni Estevadeordal, Albert Fishlow, Ernesto Gaba, Alicia Garcia-Herrero, Andrea Goldstein, Ricardo Hausmann, Bert Hofman, Louka Katseli, Nathaniel Karp, Sanjay Lall, Richard Lapper, Nicholas Lardy, Bénédicte Larre, Eduardo Lora, Ya Lan Liu, José Luis Machinea, Osmel Manzano, Diane McCollum, Alejandro Micco, Charles Oman, Jim O'Neill, Luisa Palacios, Mixin Pei, Guillermo Perry, Nicolas Pinaud, Philip Poole, Helmut Reisen, Germán Ríos, Dani Rodrik, Manuel Sánchez y David Taguas los documentos y sugerencias ofrecidos, así como la oportunidad de intercambiar ideas con ellos. También expresan su reconocimiento a los colaboradores anónimos que revisaron esta versión y contribuyeron a mejorarla. Cualquier error u omisión es de exclusiva responsabilidad de los autores.

${ }^{1}$ Las estadísticas sobre China dan pie a muchas incertidumbres. En el 2003, por ejemplo, se informó oficialmente que la tasa de crecimiento del PIB había sido de $9,1 \%$; pero, a juicio de casi todos los economistas que seguían de cerca el desarrollo chino, esa tasa superó el 11\%. En el 2005, las autoridades chinas revisaron sus estadísticas y, entre otras variables, elevaron la cifra correspondiente al crecimiento del PIB. En cambio, según Alwyn Young de la Universidad de Chicago, la tasa de crecimiento del PIB en el período 1978-1998 fue inferior en 1,7 puntos a la cifra oficial (Young, 2000 y 2003). cambio de mercado, ${ }^{2}$ el cuarto en función de su participación en el comercio mundial, y fue el principal receptor mundial de inversión extranjera directa. De mantener su crecimiento comercial, China muy pronto será la tercera economía mundial después de Estados Unidos y Alemania, y aventajará por primera vez a Japón. En 2005, la economía china ocupó el cuarto lugar a nivel mundial, superando al Reino Unido.

Tal como lo subraya la mayoría de los analistas de Wall Street, el surgimiento de China se ha convertido en el acontecimiento de la década. Tanto es así que al referirse a los 1.300 millones de consumidores de este país es de rigor recurrir a cifras que rebasan toda medida. Según Goldman Sachs, en el 2040 China superará a Estados Unidos como principal economía mundial. ${ }^{3}$ Pero es posible que gran parte de esta apreciación sea demasiado optimista, por lo que algunos analistas se han preguntado si el crecimiento de China es impulsado por una burbuja inversionista, mientras que otros han advertido que puede producirse un aterrizaje brusco o han expresado su inquietud por la fijación del valor de la moneda ${ }^{4}$ y por el sistema bancario chinos. ${ }^{5}$ Para otros analistas, el nuevo capitalismo chino no está sólidamente

\footnotetext{
${ }^{2}$ En términos de paridad del poder adquisitivo (PPA), China es la segunda economía del mundo tras Estados Unidos.

${ }^{3}$ En los últimos años, Goldman Sachs ha aplicado una estrategia agresiva para ingresar en el mercado chino. Este banco de inversiones a nivel mundial, cuya sede se encuentra en Estados Unidos administra sus negocios en Asia Pacífico a través de una subsede en Hong Kong. También tiene oficinas en Beijing y Shanghai para sus negocios en China. En Asia tiene más de 1.000 empleados, 150 de los cuales se ocupan de los negocios con China. Para los desafíos que enfrenta Goldman Sachs en China, véase Yao, Li y otros (2003).

${ }^{4}$ La preocupación por la moneda china se intensificó en el período 2003-2004, año de elecciones en los Estados Unidos (Eichengreen, 2004 y 2006).

${ }^{5}$ Para el sistema bancario chino, véase un estudio del Deutsche Bank (2004) y también un documento mimeografiado del Banco de España (2004). En los últimos dos decenios también ha aumentado el interés de los bancos extranjeros por ingresar en el sistema financiero chino, lo que indica que se han profundizado las relaciones comerciales entre China y el mundo. Entre los bancos comerciales extranjeros con mayor presencia en este país se cuentan Hong-Kong Shanghai Bank Corporation (HSBC), Citigroup, Scotia, Crédit Lyonnais y BNP Paribas. Los bancos de inversión más activos son Goldman Sachs, Morgan Stanley, Deutsche Bank, JP Morgan, UBS y Crédit Suisse First Boston (CSFB). Según estimaciones de Dealogic (importante proveedor informático británico de la banca de inversiones), dadas a conocer en diversos números del Financial Times, en el 2003 los bancos de inversión gastaron más de 200 millones de dólares en comisiones por concepto
} 
basado en la legislación, el respeto del derecho de propiedad y el libre mercado. Por último, no está claro si los bancos estatales chinos distribuyen su capital de acuerdo con criterios económicos capitalistas y, en este caso, si son vulnerables a perturbaciones negativas. Lo que sí es bastante evidente es que en casi todos los mercados se ha producido una fiebre del oro (chino). Fue lo que sucedió en el mercados de bonos, por ejemplo, con las emisiones de bonos chinos. A mediados de octubre de 2004, China emitió un bono de 1.000 millones de euros a 10 años plazo, cuya suscripción ha sido cuadruplicada con creces por grandes inversionistas europeos, desde fondos de pensiones finlandeses a administradores de activos italianos. Los márgenes de 50 a 60 puntos de base respecto de los bonos del Tesoro estadounidense son en gran medida comparables con los del lugar que ocupa Chile en la calificación del país al efecto de las inversiones e incluso con los márgenes de países desarrollados, como los 20 puntos de base que pagó España la misma semana en que se emitieron los bonos.

De todas formas, el interés de los inversionistas extranjeros por las "minas de oro" chinas es también notable. Sin embargo, los historiadores económicos tenderían a matizar la bonanza y al surgimiento de China, afirmando que no se trata de un fenómeno totalmente nuevo o sin precedentes. ${ }^{6}$ China fue la principal economía mundial durante gran parte de la historia conocida, $\mathrm{y}$ hasta el siglo $\mathrm{XV}$ registró el más alto ingreso per cápita del mundo. En 1820 representó 30\% del PIB mundial, por mucho que Europa la hubiera superado hacía largo tiempo en términos del PIB per cápita. Tal como lo han subrayado el Fondo Monetario Internacional (FMI) y el Hong-Kong Shanghai Bank Corporation (HSBC), la experiencia china en el último tiempo puede compararse fácilmente con la de Japón o la de las economías asiáticas emergentes. De hecho, la participación de China en el comercio mundial continúa siendo muy inferior a la de Japón (FMI, 2004; HSBC, 2005). Estos estudios hacen hincapié en que la participación creciente de China en el producto y la integración económica mundiales ya está generando efectos significativos en todo el mundo. Este sería el caso de Asia (Ahearne, Fernald y otros, 2003), pero también de regiones mucho más distantes como África, por ejemplo (Goldstein, Pinaud y otros, 2006).

de oferta pública inicial de acciones de empresas chinas (cifra que, sin embargo, no fue suficiente para compensarles este gasto).

${ }^{6}$ Véase una perspectiva histórica de la economía china en el estudio de Angus Maddison para el Centro de Desarrollo de la OCDE (Maddison, 1998) y en los trabajos de Shiue y Keller (2004a y 2004b).
El impacto creciente de China en América Latina también ha despertado el interés de algunas instituciones importantes que se ocupan de la región (CEPAL, 2005; CAF, 2006). Al igual que su contraparte asiática (Lin, 2004; Lall y Weiss, 2004), el Banco Interamericano de Desarrollo (BID), por ejemplo, ha multiplicado los estudios sobre los efectos del crecimiento chino en América Latina ${ }^{7}$ y ha desarrollado una densa red de investigaciones y una agenda para estimular los estudios entre Asia y América Latina. ${ }^{8}$ En la reunión anual del BID realizada en Lima se oficializó la candidatura de China como nuevo miembro de la institución, y Japón fue fijado como sede de la reunión anual de 2005. El $1^{\circ}$ de octubre de 2004 el BID, conjuntamente con el Banco Asiático de Desarrollo, organizó en Washington una importante reunión sobre China y América Latina y publicó un amplio informe al respecto (BID, 2004). Como lo subrayaron uno de los expositores y el entonces presidente del BID, Enrique Iglesias, fue la primera vez en la historia de este organismo que se realizaba un evento de esta índole.

El Banco Bilbao Vizcaya Argentaria (BBVA), importante banco europeo autorizado para operar en América Latina, también ha publicado varios estudios en que se procura evaluar el impacto de China en la región. En dos números de su publicación mensual, Latinwatch incluyó artículos relacionados con el tema. Por un lado, en Latinwatch de junio de 2003 (BBVA, 2003) apareció un artículo titulado "México y China, dos potencias exportadoras", en el cual se afirmaba que el surgimiento de China como partícipe en el comercio mundial ha sido negativo para México. Por otra parte, el número de Latinwatch correspondiente a abril de 2004 (BBVA, 2004) incluye un artículo sobre China y Argentina titulado "Potencial económico de China y oportunidades para Argentina". En el caso de Argentina, los resultados del estudio fueron contrarios a los de México. El hecho de que en la misma revista se publicaran dos estudios de casos con resultados contrapuestos es, cuando menos, sorprendente. Al parecer, por lo tanto, existe una percepción un tanto contradictoria sobre el impacto generado en América Latina por el surgimiento de China. Por una parte, los bajos costos de la mano de obra y la consiguiente competitividad de China pueden amagar a otras economías; por la otra, su enorme mercado

\footnotetext{
${ }^{7}$ Véanse, entre otros, Lora (2004a) y BID (2006).

${ }^{8}$ Véase el sitio web del Latin America / Caribbean and Asia Pacific Economics and Business Association (LAEBA), disponible en http:// www.laeba.org/index.cfm
} 
interno significa una oportunidad. ¿Es China un ángel o un demonio para América Latina?

En este trabajo evaluamos los efectos del comercio chino en América Latina a partir del surgimiento de China como actor mundial. En realidad, este artículo sigue el razonamiento de Rumbaugh y Blancher (2004), que estudia los riesgos y oportunidades que plantea el surgimiento chino, pero a nivel global. Por desgracia, el trabajo citado excluye a América Latina. La mayoría de los estudios sobre el impacto del comercio chino en los mercados emergentes centran la atención en Asia, donde según Eichengreen, Rhee y Tong (2004) las exportaciones chinas tienden a desplazar las exportaciones de otros países asiáticos. De hecho, gran parte del aumento de las importaciones estadounidenses desde China no se ha generado a expensas de países como México o los de Centroamérica (amparados por la proximidad geográfica), sino en desmedro de economías asiáticas como la de Japón y otros países emergentes. Retrocediendo al decenio de 1980, por ejemplo, en el año 1988 casi $60 \%$ de las importaciones estadounidenses de calzado provinieron de la República de Corea y la provincia china de Taiwán, y solo un escaso $2 \%$ de China. En el 2005, la participación de China aumentó a más de $70 \%$, mientras que las importaciones estadounidenses desde las economías sudcoreana y taiwanesa fueron insignificantes.

El surgimiento comercial de China como actor mundial es en muchos sentidos excepcional por su rapidez y vigor. La economía china es mucho más abierta que la de la mayoría de los mercados emer- gentes. En el 2005, la suma de sus exportaciones e importaciones de bienes y servicios superó el 70\% del PIB, mientras que en Estados Unidos, Japón o Brasil fue de $30 \%$ o menos (aunque el desempeño del comercio chino puede compararse con el de algunos países latinoamericanos como Chile o México, con cifras de 60-65\%, y también con el de algunos países desarrollados como España). Al parecer, esta tendencia se mantendría a mediano plazo gracias a la demanda externa e interna. En opinión de Soler (2003), en China el crecimiento del comercio se acompañará de una tasa de crecimiento anual de la productividad de $1 \%$ en el período 2003-2012, lo que nos lleva a pensar que el actual crecimiento chino es sostenible a mediano plazo. Es probable que la tasa de crecimiento pierda dinamismo a medida que China se desarrolle, pero de todas formas será significativa.

En el presente ensayo se estudian los efectos del crecimiento y del comercio de China tanto a corto como a mediano plazos. El trabajo se ha estructurado de la siguiente manera: la sección II siguiente hace hincapié en el surgimiento de China como actor mundial en materia de comercio, la sección III examina la estructura comercial del país y la sección IV centra la atención en la competitividad del comercio chino. La sección V se ocupa de las oportunidades de comercio a que da lugar la fuerte demanda china y estudia los aspectos geográficos y sus efectos en el comercio con China. La sección VI analiza los efectos de largo plazo del comercio chino. La sección VII, por último, presenta nuestras principales conclusiones.

\section{II}

\section{El surgimiento de China como actor}

\section{en el comercio mundial}

Los avances logrados por China desde que se abrió por primera vez a la inversión extranjera y a las reformas en 1978 han sido impresionantes. En el período comprendido entre 1978 y 2005 , la tasa media anual de crecimiento del PIB alcanzó a 9,5\%. ${ }^{9}$ En los últimos 20 años, y tras un largo período de autarquía económica, el país surgió como participante de importancia en el

\footnotetext{
${ }^{9}$ Para mayores detalles sobre estos resultados y su sustentabilidad, véase Lin (2004) y Zijian Wang y Wei (2004).
}

comercio mundial. Al respecto, podría considerarse que el ingreso de China a la Organización Mundial del Comercio (OMC) en diciembre de 2001 marcó un hito. En el período indicado, China redujo sus aranceles en forma significativa y fue incorporándose gradualmente en el comercio mundial. Actualmente, el arancel medio ponderado de China es de 6,4\%, comparado con uno de $40,6 \%$ hace 10 años (cuadro 1 ).

La participación de China en los mercados mundiales fue aumentando rápidamente durante el proceso 
China: aranceles en los últimos veinte años

\begin{tabular}{lccrc}
\hline & Promedio no ponderado & Promedio ponderado & $\begin{array}{c}\text { Dispersión } \\
\text { (desviación estándar) }\end{array}$ \\
\hline 1982 & 55,6 & - & - & - \\
1992 & 42,9 & 40,6 & 13,0 & 9,0 \\
1997 & 17,6 & 16,0 & 121,6 \\
2002 & 12,3 & 6,4 & 71,0 \\
\hline
\end{tabular}

Fuente: elaborado sobre la base de World Economic Outlook (FMI, 2004).

CUADRO 2

China: Participación de sus exportaciones en los mercados más importantes

(Porcentajes de las importaciones totales de estos mercados)

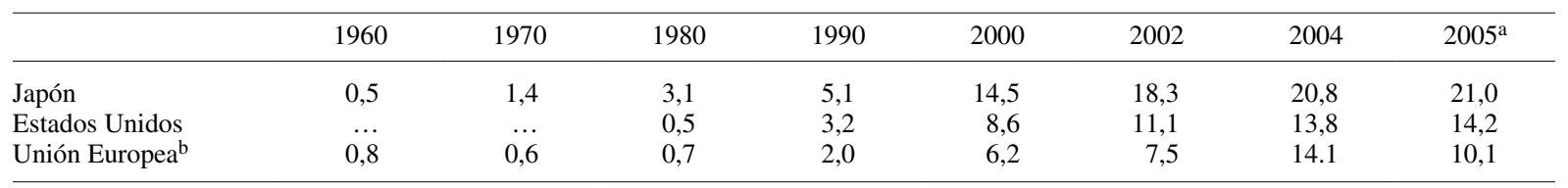

Fuente: basado en cifras del FMI (World Economic Outlook y Direction of Trade Statistics).

a 2005 (enero-junio)

b No incluye el comercio entre países de la Unión Europea.

de apertura comercial. Sin embargo, si se la compara con la de algunos países de América Latina, la tasa de crecimiento de las exportaciones chinas parece algo menos notable. En la década de 1990, por ejemplo, el incremento de las exportaciones de países como México, Chile o Costa Rica fue superior al de China durante el mismo período (Lora, 2004b). La evolución positiva de las exportaciones permitió que China aumentara su participación en los mercados desarrollados (cuadro 2). Por definición de lo que es la participación de mercado, este aumento se logró a expensas de otras economías.

Esta es una de las razones por las cuales la mayoría de los países emergentes percibe a China como un fuerte competidor comercial. ${ }^{10}$ Algunos países incluso le atribuyen los resultados poco favorables de sus exportaciones en los últimos años. ${ }^{11}$ En realidad, China está reemplazando a otros países emergentes en los mercados

\footnotetext{
${ }^{10} \mathrm{Un}$ indicador de las crecientes tensiones generadas por la competencia que ha traído consigo el surgimiento de China es el creciente número de investigaciones de que ha sido objeto por acusaciones de dumping. En los últimos años este país se ha convertido en blanco principal de tales acusaciones (véase Chu y Prusa, 2004).

${ }^{11}$ Por ejemplo, el deficiente desempeño del sector industrial en Estados Unidos, pese al significativo crecimiento económico del país en el período 2002-2004, se atribuye indirectamente a China. En un proceso para extraterritorializar la producción, las empresas estadounidenses están trasladando sus actividades manufactureras a China, debido al bajo costo de la mano de obra. En el mismo sentido, algunos analistas
}

mundiales. La percepción negativa señalada se intensificó después del 2001, fecha en que China finalmente ingresó a la OMC. La incorporación a este organismo implicó una apertura de los mercados mundiales a los productos chinos y puso aun más de manifiesto la capacidad de China para competir en ellos con éxito. La verdad es que hay una fuerte competencia entre China y otras economías que se especializan en la exportación de productos industriales de valor agregado relativamente bajo. Está claro entonces que a corto plazo emergerán algunos costos.

Para confirmar esta percepción, cabe señalar que en los últimos 20 años la participación de China en las exportaciones mundiales ha aumentado en forma acelerada. En 1980, China generó un 0,9\% de las exportaciones mundiales y en el 2002 un 5\%. En el 2003 , las exportaciones chinas se aproximaron al $6 \%$ de las exportaciones globales y a fines de 2004 el país pasó a ocupar el tercer lugar entre los exportadores mundiales (después de Estados Unidos y Alemania). Entre 1990 y 2002 las exportaciones mundiales aumentaron aproximadamente en $90 \%$ y las de China cerca de $425 \%$. La evolución de las exportaciones chinas

afirman que el mal desempeño de las exportaciones mexicanas en los últimos años se debería a la competencia de China. 
implica, por definición, que otros países están reduciendo su participación en el mercado. No hay duda de que a corto plazo se harán sentir algunos costos, ya que China puede producir bienes de poco valor agregado a un costo muy bajo, porque cuenta con mano de obra relativamente más abundante que en otras economías. Por ejemplo, en China los salarios son cuatro veces inferiores al promedio de los países de América Latina. En el 2002, el salario medio mensual en el sector manufacturero chino fue de 112 dólares, en tanto que era aproximadamente de 440 dólares en México y 300 dólares en otros centros maquiladores de Centroamérica, como Costa Rica, El
Salvador o Panamá. Con todo, es posible que estos hechos se hayan interpretado, con demasiada ingenuidad, en forma exclusivamente negativa.

Por el lado positivo, encontramos que el comercio con China genera algunos efectos favorables. Desde luego, posee un enorme mercado interno y el desarrollo del país contribuirá a que este florezca. A largo plazo, el surgimiento de China traerá beneficios provenientes del comercio. Los países en desarrollo que han establecido fuertes lazos comerciales y de inversión con China, como los del sudeste asiático, podrían salir favorecidos con este proceso.

\section{III}

\section{La estructura comercial de China}

Para analizar los efectos de corto plazo derivados de la evolución del comercio chino es preciso comenzar por examinar la estructura exportadora e importadora del país.

Lo primero que hay que destacar es que en China existe una brecha enorme entre las exportaciones y las importaciones de bienes. De hecho, la diferencia entre ambas es de 30.400 millones de dólares. Sin embargo, como se dijo en la sección anterior, esta característica de la balanza comercial china debería ser transitoria. En otras palabras, a largo plazo la balanza comercial debería ser más sostenible.

Para desarrollar esta parte del trabajo se utilizó la base de datos de la Conferencia de las Naciones Unidas sobre Comercio y Desarrollo (UNCTAD), ${ }^{12}$ que abarca 620 productos, ordenados de acuerdo con el sistema de tres dígitos de la Clasificación Uniforme para el Comercio Internacional (CUCI). Sin embargo, para fines de presentación se utilizó la clasificación de un dígito de la UNCTAD.

Por el lado de las exportaciones, en el 2004 ubicamos tres sectores clave: productos manufacturados; maquinaria y equipo de transporte, y, por último, manufacturas varias. En conjunto estos sectores representan un 87,4\% de las exportaciones totales chinas (cuadro 3 ).

Cabe subrayar el notable incremento de la partida maquinaria y equipo de transporte. En 1998, las exportaciones de esta clase de bienes alcanzaron un $28,0 \%$ del total exportado. Seis años más tarde representaron un $46,6 \%$, esto es, un aumento de 18,6 puntos porcentuales. En cambio, la participación de las manufacturas varias se está reduciendo rápidamente.

\footnotetext{
${ }^{12}$ Esta base de datos se encuentra en el sitio www.intracen.org.
}

En lo que toca a las importaciones, comprobamos que los sectores más importantes son los de productos manufacturados, maquinaria y equipo de transporte y productos químicos, que en el 2004 representaron $69,2 \%$ del total (cuadro 4). El hecho de que las exportaciones y las importaciones tengan una estructura similar muestra que hay un volumen importante de comercio intraindustrial. Esto indica que China se ha convertido en un centro regional de producción y de fabricación para la reexportación.

$\mathrm{Al}$ igual que en el caso anterior, la partida maquinaria y equipo de transporte está adquiriendo creciente importancia. En cambio, los productos manufacturados están perdiendo terreno. En rigor, si utilizamos el Sistema Interactivo Gráfico de Datos de Comercio Internacional (SIGCI) de la CEPAL, se obtienen los mismos resultados. Esta base de datos organiza la estructura comercial en manufacturas de alta tecnología, manufacturas de tecnología media, manufacturas de baja tecnología, manufacturas basadas en recursos naturales, materias primas y otras transacciones (cuadro 5).

La estructura relativamente similar del comercio sugiere que existe intercambio intraindustrial. En este caso, la participación de las manufacturas de alta tecnología está aumentando rápidamente. Por otra parte, las manufacturas de baja tecnología están perdiendo terreno en la estructura comercial, tanto en el caso de las exportaciones como en el de las importaciones.

Con todo, estos datos no ofrecen información sobre las ventajas o desventajas que genera el comercio de China. Para estudiar sus efectos en otros países se requiere un análisis más detallado. 
CUADRO 3

China: estructura exportadora

(Porcentajes de las exportaciones totales del país)

\begin{tabular}{|c|c|c|c|c|c|c|c|}
\hline & 1998 & 1999 & 2000 & 2001 & 2002 & 2003 & 2004 \\
\hline Maquinaria y equipo de transporte & 28,0 & 31,1 & 34,2 & 36,8 & 40,3 & 44,0 & 46,6 \\
\hline Manufacturas varias & 37,3 & 36,2 & 33,7 & 31,9 & 30,2 & 28,1 & 25,6 \\
\hline Productos manufacturados & 16,0 & 15,3 & 15,4 & 14,8 & 14,5 & 14,0 & 15,2 \\
\hline Productos químicos & 5,4 & 5,1 & 4,6 & 4,7 & 4,5 & 4,2 & 4,2 \\
\hline Alimentos y animales & 5,8 & 5,4 & 4,9 & 4,8 & 4,5 & 4,0 & 3,2 \\
\hline Combustibles minerales y lubricantes & 2,8 & 2,3 & 3,1 & 3,1 & 2,6 & 2,5 & 2,4 \\
\hline Productos básicos & 2,1 & 2,1 & 1,9 & 1,9 & 1,8 & 1,6 & 1,6 \\
\hline Productos en bruto (alimentos y combustibles) & 1,7 & 1,8 & 1,6 & 1,4 & 1,2 & 1,0 & 0,9 \\
\hline Bebidas y tabaco & 0,5 & 0,4 & 0,3 & 0,3 & 0,3 & 0,2 & 0,2 \\
\hline Aceites/grasas/ceras de origen animal o vegetal & 0,4 & 0,3 & 0,3 & 0,3 & 0,2 & 0,2 & 0,1 \\
\hline
\end{tabular}

Fuente: base de datos Intracen 2004, de la Conferencia de las Naciones Unidas sobre Comercio y Desarrollo y la Organización Mundial del Comercio (UNCTAD/OMC).

CUADRO 4

China: estructura importadora

(Porcentaje de las importaciones totales chinas)

\begin{tabular}{lrrrrrrr}
\hline & 1998 & 1999 & 2000 & 2001 & 2002 & 2003 & 2004 \\
\hline Maquinaria y equipo de transporte & 38,8 & 40,5 & 40,3 & 42,3 & 45,3 & 45,9 & 44,4 \\
Productos manufacturados & 22,5 & 21,2 & 19,0 & 17,7 & 17,2 & 16,2 & 13,6 \\
Productos químicos & 13,8 & 13,8 & 12,7 & 12,4 & 12,3 & 11,1 & 11,2 \\
Manufacturas varias & 7,8 & 7,3 & 6,1 & 7,7 & 7,6 & 8,6 & 9,4 \\
Materiales en bruto (excluidos alimentos y combustibles) & 7,5 & 7,6 & 8,8 & 9,0 & 7,6 & 8,2 & 9,8 \\
Combustibles minerales y lubricantes & 4,9 & 5,5 & 9,2 & 7,2 & 6,6 & 7,1 & 8,6 \\
Alimentos y animales & 2,7 & 2,2 & 2,1 & 2,0 & 1,8 & 1,4 & 1,6 \\
Productos básicos & 1,1 & 1,5 & 1,4 & 1,3 & 1,2 & 1,0 & 0,9 \\
Aceites/grasas/ceras de origen animal y vegetal & 0,6 & 0,4 & 0,2 & 0,1 & 0,2 & 0,3 & 0,4 \\
Bebidas y tabaco & 0,1 & 0,1 & 0,2 & 0,2 & 0,1 & 0,1 & 0,1 \\
\hline
\end{tabular}

Fuente: base de datos Intracen 2004, de UNCTAD/OMC.

CUADRO 5

China: estructura exportadora e importadora

(Porcentaje del total de las exportaciones e importaciones chinas)

\begin{tabular}{lrrrrrr}
\hline & 1990 & 1995 & 2000 & 2003 & 2004 & 2005 \\
\hline Estructura exportadora & & & & & & \\
Manufacturas de alta tecnología & 5,3 & 13,0 & 22,4 & 30,3 & 32,5 & 33,2 \\
Manufacturas de baja tecnología & 40,2 & 46,3 & 41,2 & 35,2 & 32,5 & 31,5 \\
Manufacturas de tecnología media & 20,8 & 18,8 & 19,6 & 20,4 & 21,7 & 22,0 \\
Manufacturas basadas en recursos naturales & 11,4 & 12,0 & 9,9 & 9,1 & 9,3 & 9,4 \\
Materias primas & 20,2 & 9,0 & 6,2 & 4,5 & 3,5 & 3,3 \\
Otras transacciones & 2,1 & 0,7 & 0,7 & 0,6 & 0,5 & 0,5 \\
Estructura importadora & & & & & & \\
Manufacturas de alta tecnología & 13,4 & 17,4 & 28,0 & 34,0 & 34,2 & 35,7 \\
Manufacturas de tecnología media & 45,9 & 42,0 & 30,4 & 31,1 & 29,4 & 27,0 \\
Materias primas & 10,8 & 10,3 & 13,7 & 11,5 & 14,5 & 16,4 \\
Manufacturas basadas en recursos naturales & 11,9 & 13,9 & 15,2 & 13,0 & 13,2 & 12,6 \\
Manufacturas de baja tecnología & 17,0 & 14,9 & 11,6 & 9,9 & 8,2 & 7,8 \\
Otras transacciones & 1,0 & 1,0 & 1,1 & 0,6 & 0,5 & 0,6 \\
\hline
\end{tabular}

Fuente: información del Sistema Interactivo Gráfico de Datos de Comercio Internacional (SIGCI) de la CEPAL. 


\section{IV}

\section{Los costos de corto plazo: la competencia comercial de China}

Aunque, a nuestro juicio, China se verá favorecida en el largo plazo por el comercio con otras economías emergentes, a corto plazo podría encarar algunos costos, en especial, debido a que está compitiendo con ellas en mercados desarrollados. En el caso de los países de América Latina, la información disponible indica que México ofrece un ejemplo paradigmático de estos costos de corto plazo. ${ }^{13}$

Para evaluar los costos de corto plazo derivados de la competencia de China, hemos utilizado dos índices de la competencia comercial. La idea es comparar la estructura exportadora de China con la de otras economías emergentes en un período determinado. Si en dos países esa estructura es bastante similar, lo más probable es que ambos compitan en terceros mercados, como el de Estados Unidos, principal destino de las exportaciones de América Latina.

Los dos índices se elaboraron utilizando la base de datos de la UNCTAD y son versiones modificadas de los conocidos coeficiente de especialización (CS) y coeficiente de conformidad (CC).

$$
\begin{gathered}
C S=1-\frac{1}{2} \sum_{n}\left|a_{i t}^{n}-a_{j t}^{n}\right| \\
C C=\frac{\sum_{n} a_{i t}^{n} a_{j t}^{n}}{\sqrt{\sum_{n}\left(a_{i t}^{n}\right)^{2} \sum_{n}\left(a_{j t}^{n}\right)^{2}}}
\end{gathered}
$$

en que $a_{i t} \mathrm{y} a_{\mathrm{ij}}$ representan la participación del producto $n$ en el total de exportaciones del país $i$ en el período $t$. En este caso, uno de los países siempre será China y el otro una economía seleccionada. Si dos países (ij) tienen exactamente la misma estructura exportadora, ambos índices son iguales a 1, en cuyo caso el potencial de competencia comercial es alto. En cambio, si los dos índices son iguales a 0 no hay coincidencia entre las estructuras. Construimos dos índices en vez de uno para

\footnotetext{
${ }^{13}$ Véase, por ejemplo, América Economía (2003) y The Wall Street Journal (2004).
}

asegurarnos de que los resultados fueran consistentes. ${ }^{14}$ Calculamos los coeficientes CS y CC comparando la competencia de China con 34 economías, 15 de las cuales corresponden a países de América Latina. El período abarcado fue 1998-2004. Naturalmente, se calcularon los valores de $C S$ y $C C$ para cada año.

En resumen, comparamos la estructura exportadora de China con la de 34 países. Realizamos esta comparación para siete años diferentes (1998-2004). Por último, utilizamos índices distintos para cada año. Con miras a presentar los resultados en la forma más sencilla posible, agregamos la información. La cifra final, que hemos denominado $\mathrm{CI}$, representa el promedio aritmético de ambos índices (cuadro 6 y gráfico 1 ).

Los resultados revisten bastante interés, ya que las cifras son relativamente bajas para todas las economías latinoamericanas, salvo México. En general, las cifras indican que en el mercado estadounidense no hay competencia directa entre China y América Latina. No es de extrañar que los países que exportan principalmente productos básicos enfrenten un menor riesgo de competencia, puesto que China es importador neto de materias primas. Entre las 34 economías estudiadas, las cifras más bajas corresponden a Paraguay, República Bolivariana de Venezuela, Bolivia y Panamá, es decir, estos países son los menos afectados por la competencia comercial de China. Brasil y Colombia podrían considerarse casos intermedios entre México y a la República Bolivariana de Venezuela.

Al comparar los países de América Latina con otras economías emergentes, en especial de Asia, se observa que, en general, la competencia de China no plantea mayores problemas. Por lo tanto, desde el punto de vista del intercambio comercial podría concluirse que los costos de corto plazo para América Latina, de haberlos, son bastante reducidos. De hecho, en la mayoría de los países latinoamericanos las exportaciones a China han aumentado notablemente. En los últimos años, por ejemplo, China ha sido el mercado de mayor crecimiento para las exportaciones de Brasil y en el 2003 le compró a este último país $80 \%$ más

\footnotetext{
${ }^{14}$ La correlación entre los dos índices es de 0,94. Esta cifra revela que ambos proporcionan la misma información.
} 

y con otros países, en Estados Unidos, 2000-2004a

\begin{tabular}{|c|c|c|c|c|}
\hline & $\begin{array}{l}\text { Coeficiente de especialización } \\
\qquad(\mathrm{CS})^{\mathrm{b}}\end{array}$ & $\begin{array}{l}\text { Coeficiente de conformidad } \\
\qquad(\mathrm{CC})^{\mathrm{b}}\end{array}$ & $\begin{array}{l}\text { Promedio } \\
(\mathrm{CI})^{\mathrm{b}}\end{array}$ & $\begin{array}{l}\text { Promedio } \\
(\text { CI 2002) }\end{array}$ \\
\hline Paraguay & 0,08 & 0,02 & 0,05 & 0,07 \\
\hline Venezuela & 0,10 & 0,03 & 0,06 & 0,10 \\
\hline Bolivia & 0,12 & 0,04 & 0,08 & 0,11 \\
\hline Panamá & 0,11 & 0,06 & 0,08 & 0,11 \\
\hline Chile & 0,14 & 0,04 & 0,09 & 0,11 \\
\hline Rusia & 0,15 & 0,06 & 0,10 & 0,12 \\
\hline Uruguay & 0,18 & 0,07 & 0,12 & 0,17 \\
\hline Perú & 0,19 & 0,08 & 0,13 & 0,17 \\
\hline Argentina & 0,20 & 0,08 & 0,14 & 0,17 \\
\hline Guatemala & 0,24 & 0,11 & 0,17 & 0,16 \\
\hline Colombia & 0,25 & 0,12 & 0,18 & 0,20 \\
\hline El Salvador & 0,31 & 0,21 & 0,26 & 0,25 \\
\hline Brasil & 0,30 & 0,21 & 0,26 & 0,28 \\
\hline Eslovaquia & 0,40 & 0,23 & 0,31 & 0,33 \\
\hline España & 0,42 & 0,22 & 0,32 & 0,34 \\
\hline Costa Rica & 0,34 & 0,32 & 0,33 & 0,29 \\
\hline India & 0,42 & 0,25 & 0,34 & 0,38 \\
\hline Japón & 0,41 & 0,35 & 0,38 & 0,38 \\
\hline Filipinas & 0,40 & 0,37 & 0,39 & 0,33 \\
\hline Bulgaria & 0,43 & 0,36 & 0,39 & 0,41 \\
\hline Croacia & 0,45 & 0,34 & 0,40 & 0,42 \\
\hline Polonia & 0,44 & 0,35 & 0,40 & 0,46 \\
\hline Turquía & 0,43 & 0,38 & 0,41 & 0,49 \\
\hline Indonesia & 0,46 & 0,39 & 0,43 & 0,42 \\
\hline Estados Unidos & 0,43 & 0,44 & 0,44 & 0,44 \\
\hline Rumania & 0,45 & 0,45 & 0,45 & 0,52 \\
\hline Singapur & 0,45 & 0,52 & 0,48 & 0,43 \\
\hline República Checa & 0,50 & 0,52 & 0,51 & 0,43 \\
\hline República de Corea & 0,50 & 0,60 & 0,55 & 0,48 \\
\hline Hungría & 0,54 & 0,66 & 0,60 & 0,55 \\
\hline Tailandia & 0,57 & 0,71 & 0,64 & 0,57 \\
\hline
\end{tabular}

Fuente: elaboración propia.

a Según orden ascendente del promedio $C I$.

b Promedio 2002-2004.

c Promedio 2000-2002.

que en el 2002. El comercio bilateral se cuadruplicó con creces en el período 2001-2004. Con todo, el intercambio estuvo altamente concentrado y en el 2005 , un $75 \%$ de las exportaciones brasileñas a China correspondieron a cinco productos básicos: soja, mineral de hierro, acero, aceite de soja y madera. Grandes empresas brasileñas - como Aracruz, principal productora de celulosa de América Latina - más que duplicaron sus ventas a China en los últimos dos años del período indicado hasta llegar a un $12 \%$ del total de sus exportaciones. ${ }^{15}$ China también

\footnotetext{
15 En mayo de 2004, el presidente Luiz Inácio Lula da Silva realizó una visita oficial a China acompañado de más de 400 ejecutivos,
}

se convirtió en uno de los principales compradores de mineral de hierro del conglomerado Companhia Vale do Rio Doce (CVRD). Un desafío importante para Brasil es el dinamismo de las exportaciones de China, país que en los próximos decenios continuará aumentando su participación en terceros mercados mediante la colocación de nuevos productos. En este sentido, tal como lo han subrayado algunos economistas brasileños (de Paiva de Abreu, 2005), a mediano plazo la competencia de China podría afectar a algunos sectores, como los de productos de hierro y acero.

siendo esta la más importante misión comercial brasileña hasta la fecha. 
GRÁFICO 1 China: competencia comercial con países de América Latina y con otros países, en Estados Unidos, 2000-2004

A. Con países de América Latina

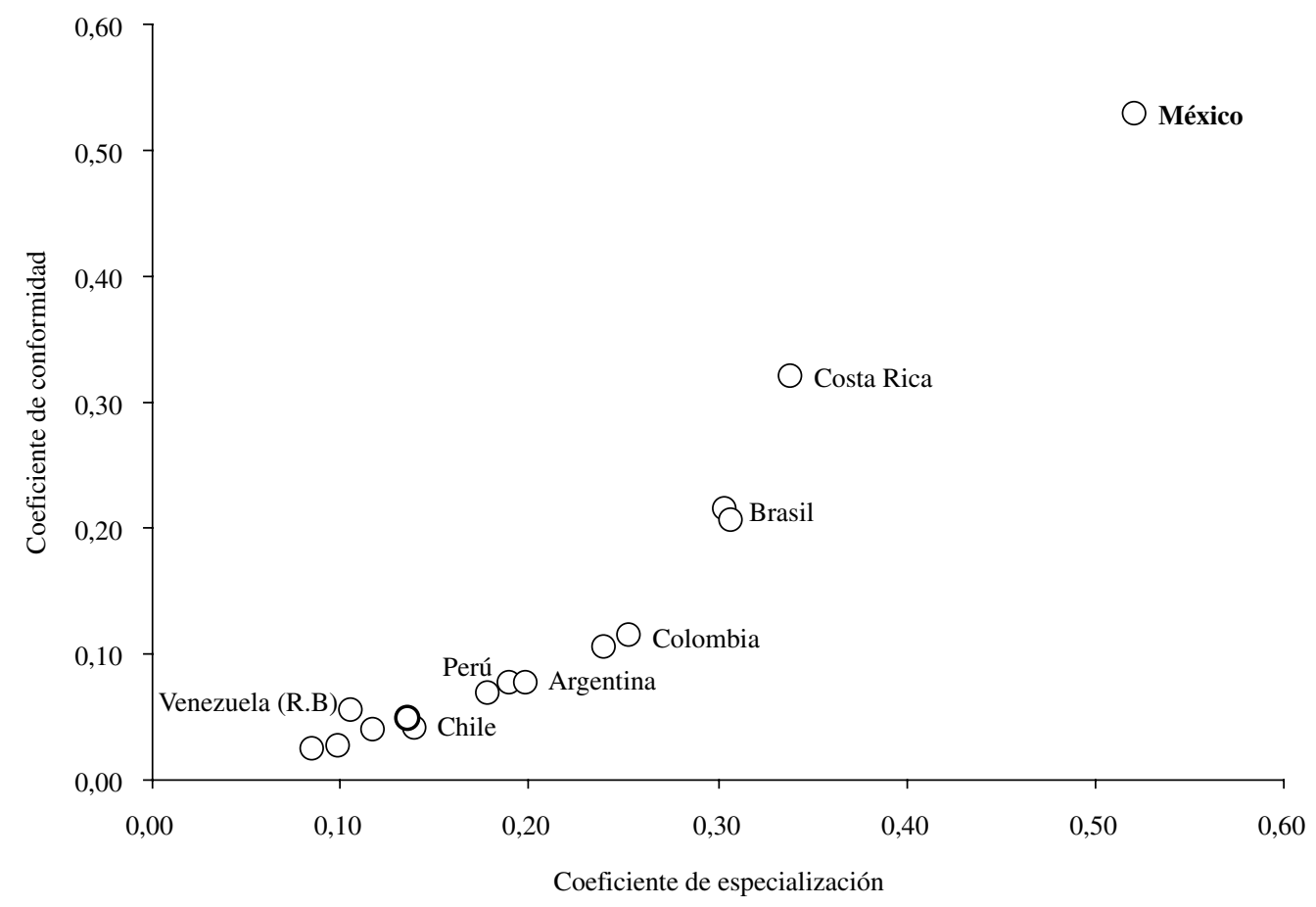

Fuente: elaboración propia.

B. Con otros países

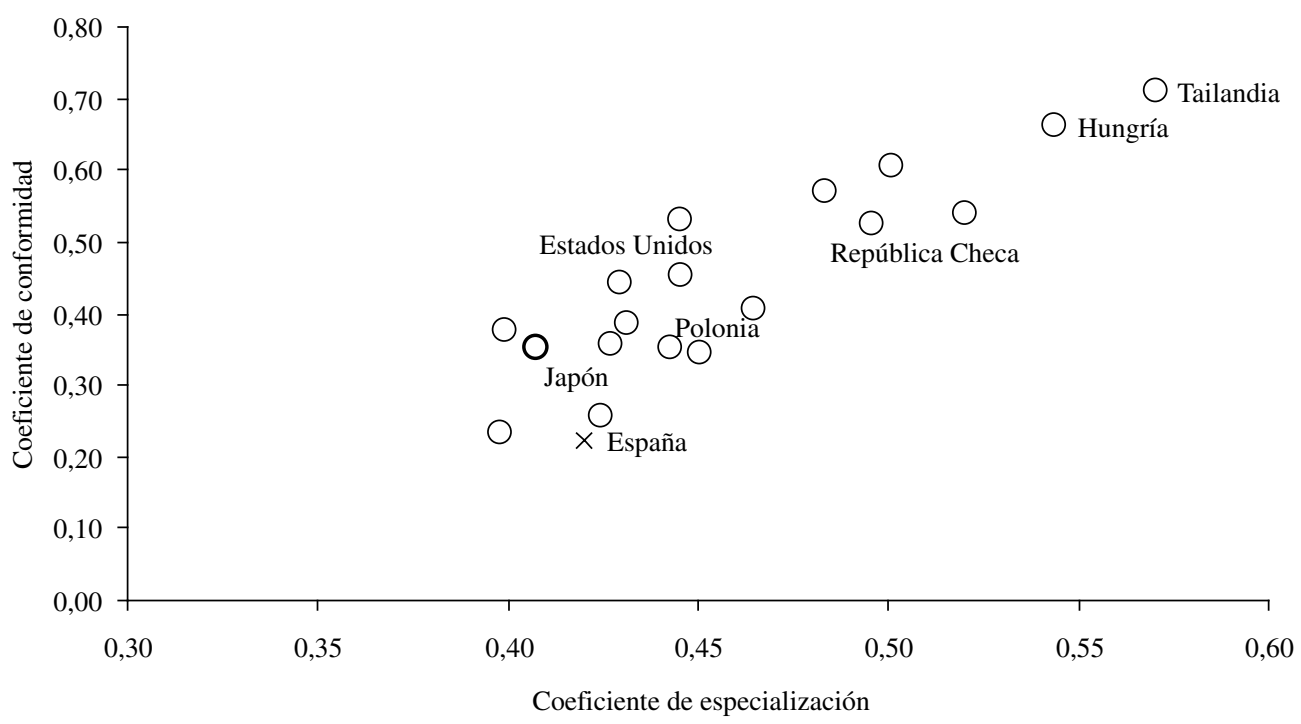

Fuente: elaboración propia. 


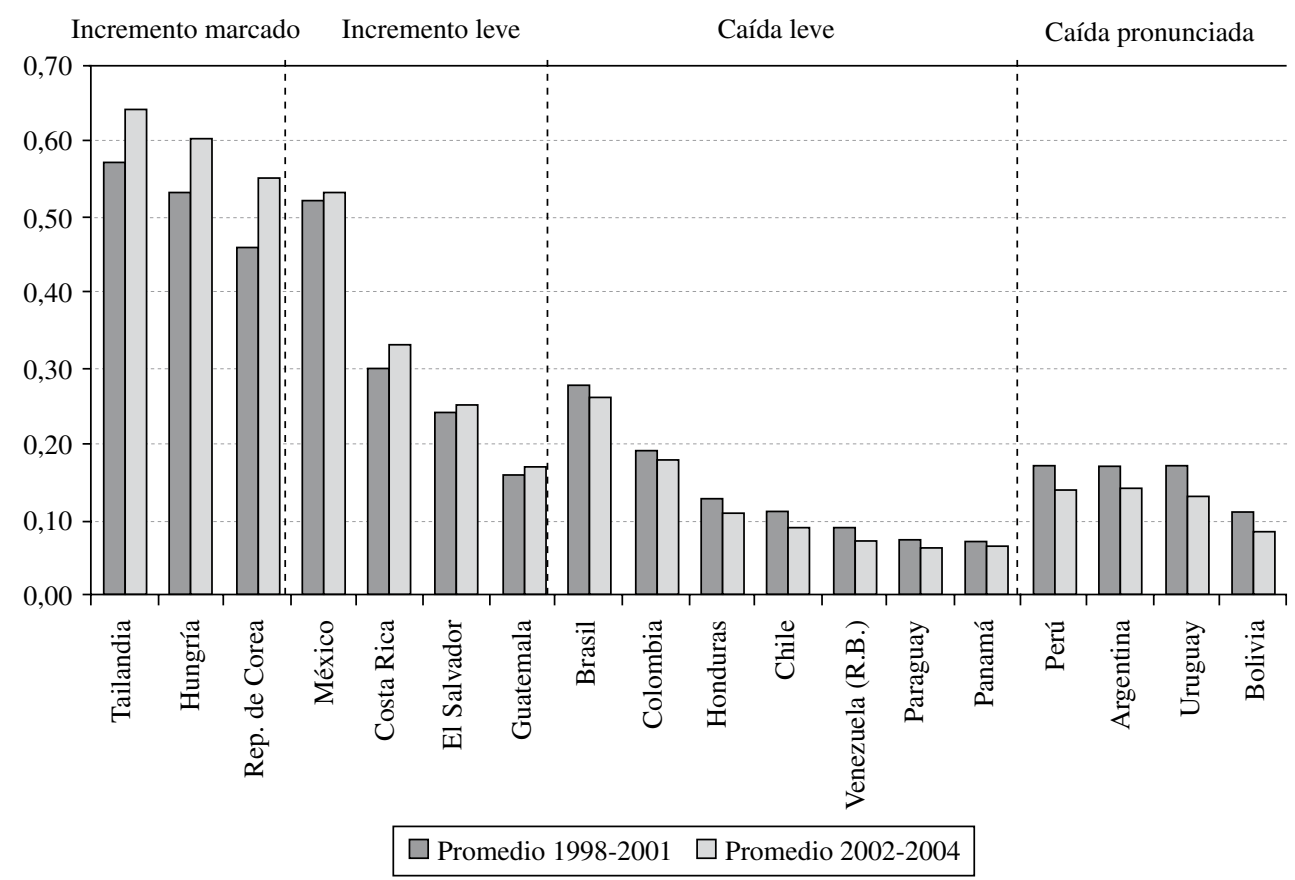

Fuente: elaboración propia.

A mayor plazo, la industria automotriz también podría enfrentar problemas.

El caso de México, es sin duda, diferente. Las cifras indican que este país encara una dura competencia comercial de China, ${ }^{16}$ inferior únicamente a la que soportan Tailandia, Hungría y la República de Corea. Al respecto, la información empírica disponible confirma los resultados oficiales. Es más, como lo indica nuestro promedio $C I$, la competencia comercial de China tiende a aumentar con el tiempo. ${ }^{17}$

En el segundo período examinado se acrecentó la competencia de China con aquellos países que ya tenían una alta competencia comercial, como Tailandia, Hungría, la República de Corea y México. En cambio, América Latina experimentó menos competencia china: el promedio $C I$ descendió en 11 de los 15 países latinoamericanos considerados (gráfico 2).

\footnotetext{
16 Soler (2003) llegó a la misma conclusión: China amenaza las exportaciones mexicanas. Sin embargo, el efecto final sobre México no depende solamente de la competencia comercial, sino también de la evolución de los flujos de capital.

${ }^{17}$ Para otros países, véase el apéndice A.
}

Nuestro análisis sugiere que China podría poner en riesgo algunas exportaciones mexicanas en los mercados externos. Una vez más, la evidencia empírica respalda esta afirmación. El principal mercado para las exportaciones de México es, con mucho, el de Estados Unidos, que en 2005 absorbió $85 \%$ de las exportaciones mexicanas. Pero según la Oficina de Análisis Económicos del Departamento de Comercio estadounidense, en el 2003 la participación de China en el mercado de Estados Unidos se elevó a 12,1\%, superando a México por primera vez en la historia. Berges (2004) examina detalladamente estas tendencias.

De acuerdo con el índice de especialización de Balassa (cuadro 7), México se especializa en la exportación de tecnologías de la información y artículos de consumo electrónicos, componentes electrónicos, prendas de vestir, equipo de transporte y manufacturas varias. ${ }^{18}$ Este índice, que incluye 14 sectores, calcula la

\footnotetext{
${ }^{18}$ Esta información se encuentra disponible en www.intracen.org.
} 
China y México: Índice de especialización de Balassa

\begin{tabular}{|c|c|c|c|c|}
\hline & China, 2002 & China, 2004 & México, 2002 & México, 2004 \\
\hline Productos de madera & 0,45 & 0,43 & 0,26 & 0,26 \\
\hline Productos de cuero & 3,70 & 3,34 & 0,34 & - \\
\hline Productos químicos & 0,46 & 0,42 & 0,35 & 0,34 \\
\hline Alimentos elaborados & 0,57 & 0,47 & 0,57 & 0,56 \\
\hline Textiles & 2,43 & 2,39 & 0,53 & 0,49 \\
\hline Minerales & 0,29 & 0,28 & 0,83 & 1,06 \\
\hline Productos básicos manufacturados & 1,01 & 0,96 & 0,76 & 0,69 \\
\hline Maquinaria no electrónica & 0,52 & 0,52 & 0,82 & 0,84 \\
\hline Alimentos frescos & 0,77 & 0,68 & 0,69 & 0,80 \\
\hline Manufacturas varias & 1,59 & 1,48 & 1,08 & 1,07 \\
\hline Equipos de transporte & 0,25 & 0,27 & 1,43 & 1,34 \\
\hline Vestuario & 3,65 & 3,46 & 1,39 & 1,29 \\
\hline Componentes electrónicos & 1,04 & 1,04 & 1,49 & 1,53 \\
\hline \multicolumn{5}{|l|}{ Tecnologías de la información y } \\
\hline artículos de consumo electrónicos & 2,00 & 2,43 & 1,81 & 1,75 \\
\hline
\end{tabular}

Fuente: elaboración propia, utilizando la base de datos Intracen 2004, de UNCTAD/OMC.

ventaja comparativa revelada de acuerdo con la fórmula propuesta por Balassa, mediante la cual la participación de un sector determinado en las exportaciones nacionales se compara con la participación del mismo sector en las exportaciones mundiales. Si el índice es superior a 1, quiere decir que el país en cuestión se especializa en ese sector. Por su parte, China se especializa en tecnologías de la información y artículos de consumo electrónicos, componentes electrónicos, prendas de vestir, manufacturas varias, textiles, productos básicos manufacturados y productos de cuero. En otras palabras, China y México se especializan en sectores análogos. Desde el punto de vista de México, el único sector en que la competencia de China no resulta significativa es el de equipo de transporte.

Algunos economistas sostienen que el modelo exportador mexicano se encontraría en peligro. En 1994, cuando entró en vigor el Tratado de Libre Comercio de América del Norte (TLCAN), México se especializaba en manufacturas de escaso valor agregado, es decir, en productos de la industria maquiladora. China también produce este tipo de bienes a un menor costo, puesto que en ese país la mano de obra es relativamente más abundante que en América Latina. Como ya se dijo, en China los salarios son cuatro veces más bajos que el promedio registrado en los países latinoamericanos. Además, las autoridades chinas fomentan este tipo de industrias de alto contenido de mano de obra mediante un programa de ventanilla única (one-stop shop), que otorga exenciones tributarias y asistencia técnica. El ingreso a la OMC le permitió a China acceder al mercado estadounidense. Lo más probable es que la competen- cia comercial de China modifique la actual estructura exportadora mexicana. Singapur, la provincia china de Taiwán y la República de Corea, por ejemplo, ya están efectuando ese cambio y aumentando el valor agregado de sus exportaciones.

Con todo, en el caso de México, si se consideran otras variables, además de los costos de producción y de la mano de obra, es difícil prever el rumbo que tomarán esos cambios y evaluar los efectos futuros del comercio. Comparado con China, México posee una clara ventaja comparativa, que es su proximidad con Estados Unidos. Los economistas han venido insistiendo en los problemas conexos de los costos de transporte y de comercio, con miras a captar la desventaja que significa la distancia (Hummels, 2001a). La distancia también introduce demoras en los procesos, originando costos de comercio, de transporte y de transacción. Sin embargo, como sostienen Harrigan y Venables (2004) y Hummels (2001b), un elemento importante del costo de la distancia en los asuntos de comercio es el tiempo que toma entregar los productos finales e intermedios. Los costos de tiempo no solo son un aspecto cuantitativamente importante de la proximidad; también tienen efectos cualitativos en la sincronización de las tareas y la entrega de los productos, y de este modo incentivan la aglomeración de las actividades. Probablemente en el caso de México haya que identificar los sectores y productos en que la distancia y el tiempo constituyan importantes ventajas comparativas y competitivas.

En un estudio pormenorizado, Evans y Harrigan (2003) desarrollaron un modelo teórico en que se atribuye mucha importancia a la entrega oportuna y, en 
consecuencia, a que los productos se fabriquen cerca de la fuente de demanda final, con lo cual los salarios serán más elevados. La entrega oportuna es un elemento clave de su modelo, puesto que permite que los comerciantes minoristas reaccionen con rapidez y eficacia a las fluctuaciones de la demanda final, sin tener que mantener costosas existencias. Esto, solo es posible cuando los productos se fabrican cerca del lugar de su consumo final. El modelo teórico señalado concuerda con algunos casos y tendencias que se dieron en la década de 1990, cuando la producción se desplazó desde lugares como China, en que el costo de la mano de obra era menor, hacia otros en que era mayor, como México. Este desplazamiento se dio, por ejemplo, entre los proveedores de prendas de vestir a Estados Unidos, especialmente en el caso de bienes cuya entrega oportuna es esencial. A partir de información detallada proveniente de una importante tienda de departamentos, los autores citados comprobaron, como lo había previsto su modelo teórico, que los proveedores que se encontraban más próximos se especializaban en la fabricación de productos en que son fundamentales el tiempo y la entrega oportuna.

En el caso de México, podría sostenerse que este Estado Parte del Tratado de Libre Comercio de América del Norte podría recuperar su ventaja estratégica, si lograra reducir los costos de comercio que se han tornado mucho más importantes que los costos de producción (Deardoff, 2004). Entre los estudios sobre el tema, algunos señalan que la elasticidad del comercio respecto de la distancia disminuye levemente, aunque la mayoría indica que la variación es escasa o nula y, lo que resulta más sorprendente, que aumenta un poco (Disdier y Head, 2004), mientras que estimaciones de la ecuación de gravedad derivadas de datos de panel para períodos prolongados apuntan a un incremento (Brun, Carrère y otros, 2005). Según estimaciones de Anderson y van Wincoop (2003), en promedio los costos de comercio casi duplican los costos de producción. Esto implica que los primeros son un factor significativo de la existencia de ventaja comparativa, talvez incluso más que los costos de producción, en los que China tiene ventaja competitiva.

En realidad, y al contrario de lo que se piensa generalmente, en los últimos decenios el efecto de la distancia en el comercio ha aumentado en vez de disminuir. ${ }^{19}$ Utilizando cifras detalladas sobre costos de transporte marítimo, Hummels (2001b) demostró que los fletes marítimos han aumentado, mientras que

${ }^{19}$ Al respecto véase Anderson y van Wincoop (2004) en Estados Unidos el valor de la carga aérea se redujo significativamente en el período 1955-1997; lo mismo constataron Glaeser y Kohlhase (2003) respecto del costo del transporte terrestre. En consecuencia, la impresión es que a lo largo del tiempo los costos del transporte no se han reducido de manera uniforme. De hecho, como lo indican Berthelon y Freund (2003), la distancia ha influido en forma importante y cada vez mayor en más de $25 \%$ de las casi 770 industrias estudiadas, esto es, en más de $30 \%$ del comercio, y prácticamente no hay industrias en que ese influjo haya mermado. Carrère y Schiff (2003) llegaron a una conclusión parecida al estudiar cómo ha evolucionado la influencia de la distancia en el comercio de los países. Comprobaron que en el período 1962-2000 el indicador "distancia del comercio" —que mide la proximidad desde un país determinado hasta el centro de la actividad económica mundial - se ha reducido en la mayoría de los países, salvo Estados Unidos. En otras palabras, a algunos países (todavía) les favorece su proximidad al centro de la actividad económica mundial, mientras que a otros les perjudica encontrarse lejos de él. Tras revisar sistemáticamente las investigaciones empíricas sobre el aumento o reducción de los efectos de la distancia a lo largo del tiempo (examinaron 856 efectos de la distancia en 55 trabajos), Disdier y Head (2004) concluyeron que en el siglo pasado los efectos negativos de la distancia en el comercio no solo no disminuyeron, sino que aumentaron.

Otro aspecto que deben enfrentar tanto México como otros países de América Latina es la necesidad de aminorar los costos de transporte y elevar la eficiencia de la infraestructura. Para la mayoría de los países de América Latina, los costos de transporte son un obstáculo aun mayor que los aranceles para ingresar al mercado de Estados Unidos. ${ }^{20}$ Tras un análisis detallado de los costos del transporte marítimo a los mercados de este país, utilizando una base de datos que abarca más de 300.000 observaciones anuales sobre los productos despachados, Clark, Dollar y Micco (2004) concluyeron que la eficiencia portuaria es un factor importante de estos costos. ${ }^{21}$ Esto tiene relevancia, ya que tanto en Asia como en América Latina la baja de las barreras arancelarias ha aumentado la importancia relativa del

\footnotetext{
${ }^{20}$ En este sentido, la carretera Panamá-Puebla — nuevo proyecto de infraestructura - podría aumentar de manera significativa el comercio entre los países centroamericanos, México y Estados Unidos.

${ }^{21}$ También indican que la distancia influye y que tiene un efecto significativo (al 1\%) y positivo en los costos de transporte; si se duplica, los costos de transporte aumentan aproximadamentt $18 \%$ (véase el apéndice B).
} 
costo del transporte como factor determinante del comercio. Si se excluye a México, los costos medios del transporte en América Latina son similares, e incluso superiores, a los de su competidor asiático.

Para algunos países, como Chile o Ecuador, los costos de transporte son más de 20 veces superiores al arancel medio que grava sus productos en Estados Unidos. La reducción de dichos costos y en consecuencia, una mayor eficiencia de la infraestructura, contribuiría a mejorar los resultados de los exportadores latinoamericanos. ${ }^{22}$ Centrándose en la relación entre la eficiencia de los puertos y los costos de transporte, Clark, Dollar y Micco (2004) encontraron que al aumentar dicha eficiencia desde el percentil 25 al percentil 75 los costos de transporte disminuyen más de $12 \%$. En el caso de México, al que favorece su proximidad a Estados Unidos, si la eficiencia de sus puertos aumentara a niveles observados en países como Francia y Suecia, se podría reducir alrededor de $10 \%$ los costos de transporte. En cuanto a Brasil o Ecuador, según estimaciones de los autores citados, en estas circunstancias los costos del transporte marítimo caerían más de $15 \%$. Los puertos de América Latina se cuentan entre los más ineficientes, a lo que hay que agregar que la región enfrenta serios problemas en lo que respecta al funcionamiento del sistema aduanero, con demoras medias de siete días en el desaduanamiento de mercancías (los puertos peor calificados al respecto son los de Ecuador y Venezuela, donde este proceso tarda 15 y 11 días, respectivamente); que el costo de la manipulación de los contenedores dentro de los puertos es elevado, y que existe una fuerte actividad del crimen organizado en la infraestructura portuaria. Todo lo anterior indica que hay amplio margen para mejoras. En general, si se aumenta la eficiencia portuaria desde el percentil 25 al 75, los costos de transporte marítimo disminuirán más de $12 \%$, lo que a juicio de los autores citados, equivale a una distancia de 5.000 millas.

\section{V}

\section{Oportunidades a corto plazo: la vigorosa demanda china}

Como se ha mostrado, los efectos del comercio chino en América Latina, salvo algunas excepciones, son en general positivos. E incluso para países como México, que enfrentan una creciente presión competitiva en el mercado estadounidense, China podría constituir, al menos en teoría, una oportunidad, en un posible mercado exportador.

Para evaluar los beneficios a que podría dar lugar la creciente demanda china, construimos dos índices. $\mathrm{Al}$ igual que en el caso anterior, utilizamos la base de datos de la UNCTAD, que abarca 620 productos diferentes. Estos índices comparan la estructura exportadora de 15 países de América Latina con la estructura importadora de China. Si las exportaciones de un país determinado se asemejan a las importaciones de China, quiere decir que habría un incremento potencial del comercio de las economías latinoamericanas. Cabe señalar que, por mucho que el valor de los índices se aproxime

\footnotetext{
22 Limao y Venables (2000) demostraron que un alza de $10 \%$ en los costos de transporte reduce más de $20 \%$ los volúmenes de comercio. También subrayaron que las deficiencias de infraestructura originan más de $40 \%$ de los costos de transporte previstos.
}

a 1 , no necesariamente habrá intercambio comercial entre China y el país de América Latina de que se trate. Lo que debemos destacar en este caso es que existe un beneficio potencial y una evidente oportunidad de comercio.

Cabe reiterar que los índices son versiones modificadas del coeficiente de especialización $(\mathrm{CSm})$ y del coeficiente de conformidad $(\mathrm{CCm})$ :

$$
\begin{gathered}
C S m=1-\frac{1}{2} \sum_{n}\left|a_{i t}^{n}-a_{j t}^{n}\right| \\
C C m=\frac{\sum_{n} a_{i t}^{n} a_{j t}^{n}}{\sqrt{\sum_{n}\left(a_{i t}^{n}\right)^{2} \sum_{n}\left(a_{j t}^{n}\right)^{2}}}
\end{gathered}
$$

en que $a_{i t}$ representa la participación del producto $n$ en el total de exportaciones del país latinoamericano $i$ en el período $t$. Por otra parte, $a_{j t}$ representa la participación del producto $n$ en el total de las importaciones chinas durante el período $t$. Ambos índices son iguales a 1 si las importaciones chinas 
CUADRO 8

Países latinoamericanos: Comercio potencial con China

\begin{tabular}{lcccc}
\hline & $\mathrm{CSm}^{\mathrm{a}}{ }^{\mathrm{b}}$ & $\mathrm{CCm}^{\mathrm{a} b}$ & $\mathrm{Clm}^{\mathrm{b}}$ & $\mathrm{Clm} 2002^{\mathrm{c}}$ \\
\hline Panamá & 0,09 & 0,03 & 0,06 & 0,08 \\
Honduras & 0,13 & 0,04 & 0,08 & 0,08 \\
Paraguay & 0,10 & 0,08 & 0,09 & 0,10 \\
Perú & 0,16 & 0,09 & 0,13 & 0,15 \\
Bolivia & 0,16 & 0,09 & 0,13 & 0,14 \\
Uruguay & 0,18 & 0,07 & 0,13 & 0,15 \\
Chile & 0,17 & 0,12 & 0,15 & 0,17 \\
El Salvador & 0,21 & 0,11 & 0,16 & 0,17 \\
Guatemala & 0,24 & 0,14 & 0,19 & 0,16 \\
Venezuela (Rep. Bol. de) & 0,17 & 0,30 & 0,23 & 0,25 \\
Costa Rica & 0,24 & 0,25 & 0,25 & 0,25 \\
Colombia & 0,25 & 0,28 & 0,27 & 0,27 \\
Argentina & 0,31 & 0,23 & 0,27 & 0,30 \\
Brasil & 0,40 & 0,33 & 0,36 & 0,36 \\
México & 0,44 & 0,50 & 0,47 & 0,47 \\
\hline
\end{tabular}

Fuente: elaboración propia.

a Según orden ascendente del Clm.

b Promedio 2002-2004.

c Promedio 2000-2002.

coinciden exactamente con las exportaciones del país latinoamericano considerado. También en este caso construimos dos índices para asegurar que nuestros resultados son coherentes. En esta parte del trabajo procedimos de la misma manera que en la sección anterior. Una vez más, el período estudiado fue 19982004 y calculamos los valores de $C S m$ y $C C m$ para cada año. Por último, a fin de facilitar la presentación de los datos, reunimos esta información en un nuevo promedio modificado CIm (cuadro 8).

Los resultados no parecen muy alentadores, principalmente porque los países de América Latina son exportadores de productos básicos y, por lo tanto, su comercio potencial con China se limita a una pequeña canasta de productos. En otras palabras, dada la estructura exportadora de la región, hay escasas probabilidades de comercio intraindustrial de China con América Latina, salvo en los casos de México y Brasil.

Para simplificar, en el cuadro 7 que figura antes solo presentamos el índice de especialización de las exportaciones de dos países: China y México. En el cuadro A.2 (apéndice A) se presentan 11 países latinoamericanos y se destacan las cifras correspondientes a los sectores en que se ha especializado América Latina y no se ha especializado China: productos de madera, alimentos elaborados, minerales y productos perecibles. Estos sectores son claramente de materias primas. El Salvador y Guatemala también se especia-
CUADRO 9

China y mundo: Tasa media anual de crecimiento de las importaciones, 1997-2004 (En porcentajes)

\begin{tabular}{lcc}
\hline & China & Mundo \\
\hline Petróleo & 24,4 & 2,9 \\
Cobre & 18,4 & 4,0 \\
Soja $^{a}$ & 20,5 & 6,9 \\
\hline
\end{tabular}

Fuente: elaboración basada en datos del Departamento de Agricultura de Estados Unidos, World Metal Statistics y British Petroleum.

a Promedio 2001-2004.

lizan en productos químicos ${ }^{23}$ y México en equipo de transporte.

En general, América Latina exporta productos básicos, lo que significa que solo podrá incrementar su comercio en un número reducido de productos. Además, dada la creciente demanda china de materias primas, el comercio con este país podría requerir una mayor especialización en este tipo de bienes, aumentando el riesgo de que algunos países se vean atrapados en la exportación de materias primas y no puedan avanzar en la cadena de valor agregado. De hecho, China también se está convirtiendo en comprador a nivel mundial de materias primas en algunos mercados (cuadro 9). En 2003, fue el principal importador mundial de algodón, cobre y soja y el cuarto importador de petróleo. ${ }^{24} \mathrm{La}$ demanda china de productos primarios ha continuado aumentando, especialmente la de cobre y soja, que ha crecido anualmente a razón de $50 \%$. En el caso del petróleo, la tasa de crecimiento se aproxima al $20 \%$ anual. En el 2003, China se convirtió en el principal importador mundial de cobre, elevando las exportaciones de Chile y Perú. La combinación de una gran expansión industrial y de una economía floreciente también contribuyó a generar una fuerte demanda de petróleo que los proveedores están procurando satisfacer y que hizo que China sobrepasara a Japón, y se convirtiera en el segundo consumidor mundial de este producto después de Estados Unidos. En el 2003, la tercera parte del incremento del consumo diario mundial de petróleo se debió a China.

\footnotetext{
${ }^{23}$ Sin embargo, China importa productos químicos principalmente desde países del sudeste asiático. Este es uno de los sectores en que se especializan esas economías de Asia. Véase Ianchovichina y Walmsley (2003). ${ }^{24}$ En cifras de 2004, la participación de China en las importaciones mundiales de soja se elevó a 34,3\%, comparada con 7,4\% en 1997. En el caso del cobre, en el 2004 las importaciones chinas se elevaron a $25,3 \%$ del total, mientras que en 1997 representaron un 5,0\%. Por último, en 2004 las importaciones chinas de petróleo ascendieron a $7,2 \%$, mientras que en 1997 representaron un 2,3\% de las importaciones mundiales de este producto.
} 
Aunque el intercambio se concentra en un número reducido de productos básicos, la vigorosa demanda china de materias primas es auspiciosa para América Latina. En términos económicos, podría decirse que se trata de un shock de demanda positivo. Aun más, genera efectos favorables en la región, por mucho que no aumente su comercio directo con China. Ello obedece a que los productos básicos son bienes casi homogéneos. Por ejemplo, si en China aumenta la demanda de crudo, los países productores de petróleo deberían aumentar su producción; de lo contrario, subirán los precios. Desde 2004, la creciente necesidad de petróleo de China ha estado contribuyendo a elevar los precios de este producto a sus mayores niveles desde que empezó a transarse en los mercados de futuro del New York Mercantile Exchange, en 1983. Según el Organismo Internacional de Energía de la OCDE, con sede en París, en el primer trimestre de 2004 un millón de los 1,8 millones de barriles en que aumentó el consumo diario de petróleo correspondió a China. Entre 2000 y 2004, China dio cuenta de casi $40 \%$ del crecimiento total de la demanda mundial de petróleo.

En América Latina, los cuatro principales productos básicos son: cobre, petróleo, soja y café. Estos bienes representan $66 \%$ de las exportaciones latinoamericanas de materias primas. China absorbe parte importante de ellas, salvo en el caso de las de café.
CUADRO 10

América Latina (siete países): composición de las exportaciones

(En porcentajes de las exportaciones de cada país)

\begin{tabular}{lcccc}
\hline & Alimentos & Combustibles & Metales & Manufacturas \\
\hline México & 6 & 10 & 2 & 81 \\
Brasil & 31 & 1 & 9 & 54 \\
Argentina & 49 & 12 & 2 & 34 \\
Colombia & 32 & 31 & 1 & 31 \\
Perú & 35 & 7 & 39 & 17 \\
Chile & 25 & 1 & 48 & 16 \\
Venezuela & 2 & 83 & 2 & 12 \\
$\quad$ (Rep. Bol. de) & & & & \\
\hline
\end{tabular}

Fuente: elaboración basada en datos de LatinFocus (2004).

Otro elemento de interés es el hecho de que América Latina es un importante productor mundial de productos básicos. La región genera $47 \%$ de la producción mundial de soja, $40 \%$ de la de cobre y $9,3 \%$ de la de crudo, y a corto plazo la fuerte demanda china constituye una oportunidad para la mayoría de los países de América Latina, que se especializa en la exportación de esta clase de productos. De mantenerse esta demanda, lo más probable es que la región se vea favorecida. Sin embargo, cabría esperar una mayor especialización, ya que, de lo contrario, aumentará la dependencia de América Latina de los productos básicos y los países de la región seguirán estando expuestos a los vaivenes de la relación de intercambio.

\section{VI}

\section{Efecto a largo plazo de China en el comercio}

La interpretación negativa del fenómeno chino, planteada anteriormente, es que este ha generado un shock transitorio de demanda. A largo plazo, tal como lo predice la teoría económica, la evolución positiva de la economía china y el incremento del comercio mundial beneficiaría a los demás países. Al respecto, el World Economic Outlook (FMI, 2004) presenta dos escenarios alternativos en que se examina la influencia china en el comercio y el crecimiento mundiales. Sin embargo, los resultados deben mirarse con cautela, ya que a largo plazo ambos escenarios muestran efectos positivos en el resto del mundo. La mayor demanda generada por el crecimiento acelerado de China favorecerá a la mayoría de las regiones, aunque en menor medida a aquellas en que la mano de obra enfrenta relativamente más competencia de ese país. Además, en el presente trabajo se hace hincapié en que los países más favorecidos serán aquellos de estructura más flexible. Estos resultados son similares a los obtenidos por Ianchovichina y Martin (2003).

Sin embargo, cabe destacar que no es primera vez que surge un nuevo actor en el comercio mundial. ${ }^{25}$ Para ilustrar este punto, podríamos comparar la situación actual con la experiencia japonesa de las décadas de 1950 y 1960 (Yang, 2003; HSBC, 2005). A comienzos del siglo XXI, Japón es una economía clave que genera alrededor de 9\% del PIB mundial. Sin embargo, después de la segunda guerra mundial, Japón quedó en ruinas. En esa época, se caracterizaba por el nivel relativamente

\footnotetext{
${ }^{25}$ Véase, por ejemplo, World Economic Outlook (FMI, 2004). En dicho número también se examina el surgimiento del este asiático.
} 
GRÁFICO 3 Japón y China: participación en el producto interno bruto mundial (Porcentaje del PIB mundial)

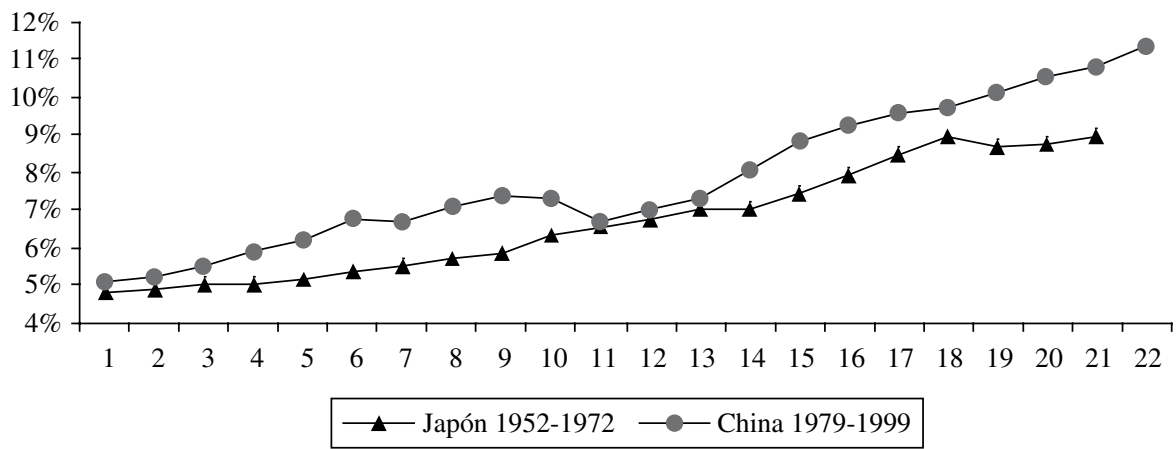

Fuente: elaboración propia a partir de la base de datos de Summers y Heston.

bajo de los salarios. Durante más de 20 años aplicó una política económica orientada a impulsar el crecimiento y las exportaciones, gracias a la cual llegó a convertirse en la segunda economía mundial. Actualmente se reconoce que los buenos resultados de la economía japonesa se vieron favorecidos por la evolución de la economía mundial en su conjunto (incluida la de América Latina).

En cierto sentido, la evolución de la economía china se asemeja a la experiencia japonesa de los años mencionados, de tal forma que hay clara coincidencia entre ambos países. La información disponible para China en el período 1979-1999 coincide con la del período de mayor crecimiento en Japón: 1952-1972. En estos períodos, ambos países crecieron a un ritmo similar, con un promedio de $8,5 \%$. Además, el crecimiento anual medio del comercio ${ }^{26}$ se aproximó al $13 \% .^{27}$

Sin embargo, no solo el comercio y el crecimiento evolucionaron de manera análoga en los períodos señalados: también se asemejó el peso de ambos países en la economía mundial. En promedio, han contribuido al crecimiento global alrededor de 0,6 puntos porcentuales al año. Dicho de otra manera, en el período 1952-1972 el PIB mundial creció a un promedio de 5,8\%, del cual 0,6 punto porcentuales correspondieron al PIB de Japón. Por su parte, en el período 1979-1999 la economía mundial creció a una tasa media anual de $3,7 \%$, de la cual 0,6 puntos porcentual correspondió al crecimiento de China (gráfico 3).

\footnotetext{
${ }^{26}$ En este ensayo definimos el comercio como la suma de las exportaciones y las importaciones.

${ }^{27}$ Se utilizó la base de datos de Summers y Heston (PWT 6.1). Véase Heston y Summers (1997).
}

Sin embargo, al hacer esta comparación surgen algunas diferencias importantes. La composición del producto interno bruto de Japón a principios del decenio de 1950 era similar a la del PIB de China a comienzos de la década de 1980 (cuadro 11): alrededor de 60\% correspondió a consumo, cerca de $15 \%$ a inversiones y más de $25 \%$ a exportaciones netas. ${ }^{28}$ Esta composición fue cambiando significativamente a lo largo de los períodos mencionados. En el caso de Japón, hubo una caída de la participación del consumo y las exportaciones netas en el PIB, que se compensó con las inversiones. En cambio, en el caso de China disminuyó el consumo y aumentaron las exportaciones netas y las inversiones.

\section{CUADRO 11 \\ Japón y China: Componentes del producto interno bruto \\ (En porcentajes del PIB total)}

\begin{tabular}{lcc}
\hline Japón & 1953 & 1972 \\
\hline Consumo & 60 & 53 \\
Inversiones & 14 & 35 \\
Exportaciones netas & 26 & 11 \\
\hline China & 1979 & 1999 \\
\hline Consumo & 57 & 47 \\
Inversiones & 17 & 21 \\
Exportaciones netas & 27 & 32
\end{tabular}

Fuente: base de datos de Summers y Heston.

\footnotetext{
${ }^{28}$ En este trabajo definimos las exportaciones netas como la diferencia entre las exportaciones y las importaciones en valores reales.
} 
Estas cifras explican por qué China es percibida más bien como rival y no como asociado comercial, pues demuestran que exporta mucho más de lo que importa. Por lo tanto, el resto de los países tiene la impresión de que el crecimiento chino no se difunde. Sin embargo, esta situación no es sostenible a largo plazo, ya que con el tiempo las importaciones chinas aumentarán enormemente y caerán sus exportaciones netas. ${ }^{29}$ De hecho, según datos de la OMC, en el 2005 las importaciones chinas de bienes ascendieron a $6,1 \%$ de las importaciones mundiales, mientras que sus exportaciones correspondieron a 7,3\% del total. La diferencia entre unas y otras ascendió a 101.900 millones de dólares, cifra equivalente a tres veces el PIB nominal de Ecuador. Hoy, a mediados de la década del 2000 , los productores chinos absorben importaciones con avidez e imponen los precios mundiales de casi todos los productos, desde el cobre hasta los microchips.

Como otra diferencia importante entre China y Japón en los períodos considerados, cabe señalar que la economía japonesa era más desarrollada mientras que la china era, y sigue siendo, una economía en desarrollo (gráfico 4). En el 2000, el PIB chino estuvo casi un $50 \%$ por debajo del promedio mundial. Según la base de datos de Summers y Heston, ${ }^{30}$ el PIB per cápita de China se asemeja al de Ecuador. Esto indica que, pese a su notable desempeño en los últimos 20 años, China podría tardar algún tiempo en profundizar el proceso
CUADRO 12

China y América Latina: participación proyectada en el PIB mundial, 2002-2020 (Porcentajes)

\begin{tabular}{lrrr}
\hline & 2002 & 2010 & 2020 \\
\hline China & 12,7 & 21,1 & 40,1 \\
América Latina & 7,9 & 7,9 & 8,0 \\
\hline
\end{tabular}

Fuente: elaboración propia.

de convergencia. En otras palabras, lo más probable es que siga registrando una alta tasa de crecimiento durante largo tiempo.

$\mathrm{Al}$ respecto, hemos realizado algunas proyecciones sencillas para evaluar la ponderación de China en la economía mundial en el futuro (cuadro 12). ${ }^{31} \mathrm{En}$ el decenio de 1990, China creció a una tasa media de $10,1 \%$, el mundo a $3,3 \%$ y América Latina a 3,4\%. De mantenerse estas tasas durante los próximos 20 años, China se convertirá en la principal economía mundial, superando con mucho a Estados Unidos. ${ }^{32}$

Por otra parte, en el 2002 las importaciones chinas correspondieron a $4,4 \%$ de las importaciones mundiales. En la década de 1990, crecieron a una tasa media de 16\%, mientras que las importaciones mundiales (exceptuada China) aumentaron alrededor de $7 \%$. De mantenerse estas cifras, en el 2010 un $8 \%$ de las importaciones

GRÁFICO 4

Japón y China: producto interno bruto per cápita

(En porcentajes del PIB per cápita mundial)

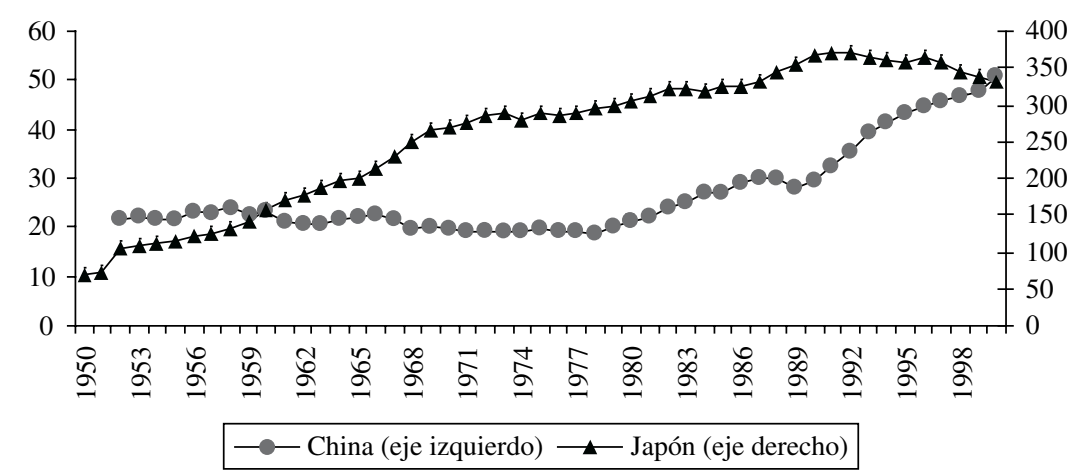

Fuente: base de datos de Summers y Heston.

\footnotetext{
${ }^{29}$ Ianchovichina y Martín (2001) comparten esta opinión respecto del futuro de las exportaciones netas. Prevén que se producirá un aumento significativo de las importaciones chinas.

${ }^{30}$ El PIB per cápita se calcula en función de la paridad de poder adquisitivo.
}

\footnotetext{
${ }^{31}$ Para estos efectos, se utilizó la base de datos del FMI.

${ }^{32}$ Véase más información sobre las proyecciones relativas al crecimiento chino en Wilson y Purushothaman (2003), Gaulier y Ünal-Kesenci (2005) y Goldman Sachs (2005).
} 
mundiales corresponderá a China y en el 2020 la cifra se habrá elevado a $18 \%$.

Es difícil prever con exactitud cuáles serán los efectos a largo plazo de la participación de China en otras economías y en el comercio internacional. Con todo, sabemos que, en general, ellos serán positivos. Pero también es cierto que podrían ser asimétricos.
La competencia china podría beneficiar a algunos sectores y perjudicar a otros. Sobre todo, China tiene ventajas competitivas en los sectores con alto contenido de mano de obra y en estas circunstancias los beneficios potenciales serán menores. Lo contrario sucederá en los sectores con alta densidad de capital. ${ }^{33}$

\section{VII \\ Las relaciones comerciales entre China y América Latina en un contexto más amplio}

En general, a corto y mediano plazo los efectos del comercio chino en América Latina son positivos. Los resultados de nuestro estudio coinciden con los de otras investigaciones, como la realizada por economistas del FMI y por otros economistas (Lall y Weiss, 2004). En promedio, y desde el punto de vista de los efectos del comercio, América Latina se verá favorecida por la mayor demanda y crecimiento de China. En términos comparativos, como lo subraya el FMI, el único perdedor absoluto será Asia meridional, mientras que en América Latina los efectos en materia de bienestar serán positivos. Por ejemplo, se prevé que hacia 2020 los efectos de la mayor integración de China en sectores como la agricultura de la región serán claramente positivos, con un crecimiento del producto agrícola de $4 \%$. En cambio, sin duda, se verán perjudicados sectores como los textiles, así como los países que se especializan en la exportación de manufacturas con alto contenido de mano de obra. Sin embargo, habrá que realizar estudios más detallados, en especial respecto de los efectos del comercio chino en el mercado interno de países latinoamericanos como México, por ejemplo.

En lo que se refiere a las relaciones comerciales, en los últimos 10 años China y América Latina han estado empeñadas en profundizarlas. ${ }^{34}$ De acuerdo con estadísticas chinas, el volumen del intercambio entre ambos países aumentó de 2.000 millones de dólares a comienzos de la década de 1990 a 15.000 millones en el año 2001. El comercio entre Brasil y China se ha casi triplicado desde el 2000, lo que constituye una bendición para la endeudada economía brasileña y especialmente para los exportadores de soja, acero y mineral de hierro, productos que representaron dos tercios de las exportaciones totales brasileñas. En general, América Latina posee una abundancia de productos básicos que estimula las sinergias con las necesidades de China y su estrategia para asegurar las importaciones de alimentos y energía que requiere para evitar la escasez.

No obstante, es posible que una de las consecuencias del rápido aumento de la demanda china en América Latina no sea tan positiva. Ante todo, el incremento cada vez mayor de la demanda de productos básicos desde China ha hecho que los países latinoamericanos acentúen su especialización en estos bienes. Estos se han caracterizado tradicionalmente por una marcada inestabilidad de precios, lo que también podría contribuir a acrecentar la volatilidad de los ingresos fiscales. Segundo, al intensificar sus vínculos comerciales con China, América Latina ha quedado más expuesta a la evolución de esta economía asiática. En el 2003, los embotellamientos en la entrega de los productos y la demanda de China contribuyeron a elevar los precios de las materias primas y de los productos básicos, pero la industria china está sujeta a vaivenes propios de períodos de bonanza y recesión. Además, en los últimos años han surgido tensiones entre Brasil y China a causa del poder cada vez mayor de este último país para fijar precios en mercados clave para Brasil, como los de mineral de hierro y soja. Por otro lado, la creciente dependencia china de las exportaciones latinoamericanas también obliga a la región a mantenerse atenta a la dinámica del crecimiento de Asia y China. Según la CEPAL, en el 2003 China se convirtió en el segundo destino principal de las exportaciones brasileñas, lugar que conserva hasta

\footnotetext{
${ }^{33}$ Véase World Economic Outlook (FMI, 2004).

${ }^{34} \mathrm{Sin}$ embargo, los contactos comerciales entre China y América Latina no son algo nuevo. Datan de la década de 1570, época en que empezó a florecer el comercio sino-latinoamericano a través del Pacífico gracias a las exportaciones chinas de seda, porcelana e hilo de algodón a México y Perú vía Manila (véase Shixue, 2004).
} 
la fecha. ${ }^{35}$ En el 2004, las ventas a China generaron la mitad de los mayores ingresos que obtuvo Brasil por concepto de exportaciones. Así, pues, China se está convirtiendo en importante impulsor del crecimiento brasileño y en responsable de la cuarta parte de la meta oficial de crecimiento del PIB de Brasil. Dado que China está procurando aminorar el sobrecalentamiento de su economía, el crecimiento de las exportaciones brasileñas podría amortiguarse.

Otro tema que merece mayor estudio, y que no se examina en este trabajo, es el de las corrientes de capital. Mientras que en América Latina la inversión extranjera directa (IED) tambalea, en China florece. Entre el 2001 y el 2003, en México dicha inversión cayó de casi 27.000 millones de dólares a 11.000 millones, aunque repuntó en el 2004 y el 2005. En Brasil también se redujo marcadamente en el 2003, con una baja de 52\% respecto del año anterior (frente a $30 \%$ en México en el mismo período). Entretanto, China se ha convertido en el principal receptor mundial de IED, con niveles cercanos a 55.000 millones de dólares en el 2003 (casi el doble de los escasos 36.500 millones que recibieron los países de América Latina en su conjunto ese mismo año) $)^{36}$ y de alrededor de 60.000 millones en el 2004 y el 2005. Esto quiere decir que en los últimos tres años entraron a China semanalmente más de 1.000 millones de dólares de inversión extranjera directa. ${ }^{37}$

Según Xiao (2005), parte importante de las corrientes de IED que ingresan a China corresponde a movimientos de entrada y salida (round-tripping). En opinión de los especialistas, los movimientos de este tipo podrían alcanzar a la cuarta parte del total de la afluencia de IED a China. Sin embargo, la IED procedente de otras regiones va en aumento. En el 2002, las empresas estadounidenses ya invertían en China diez veces más que 10 años antes. La posibilidad de acceder a un enorme mercado interno de 1.300 millones de consumidores ha precipitado a numerosas empresas a invertir en China, no obstante que en ese país el capitalismo no tiene raigambre sólida en la legislación, la protección de los derechos de propiedad y el libre mercado. ${ }^{38}$

\footnotetext{
35 Véase CEPAL (2004a).

${ }^{36}$ Véase CEPAL (2004b). En el 2003, la afluencia de IED a China casi alcanzó el máximo recibido por América Latina (88.000 millones de dólares en 1999).

${ }^{37}$ Sobre la inversión extranjera directa en China, véase el estudio de un economista del MIT, Huang (2003). Véanse también las audiencias pertinentes del Congreso de Estados Unidos, disponibles en http://www. cecc.gov/pages/ hearings/ 092403/huang.php

${ }^{38} \mathrm{Sin}$ embargo, como lo revelan los crecientes conflictos entre extranjeros y sus asociados chinos, invertir en China podría convertirse en una actividad riesgosa. En el 2004, por ejemplo, la agroquímica suiza Syngenta demandó a un competidor chino por el supuesto uso
}

Algunos estudios indican que el proceso de plena de la enorme fuerza laboral china en la división internacional del trabajo ha dado lugar a una "desviación de los flujos" en su favor. ${ }^{39}$ En el caso de países asiáticos como Filipinas, Indonesia, Malasia y Tailandia, este proceso podría provocar una pérdida significativa de bienestar si la inversión extranjera directa se desviara desde ellos hacia China, ya que correrían el riesgo de desindustrializarse y de recaer en el papel de exportadores de productos básicos que desempeñaban en las décadas de 1950 y 1960 (McKibbin y Thye Woo, 2003). Sin embargo, tanto los estudios como la información disponible revelan que las consecuencias son más bien menores. Respecto del largo período comprendido entre 1984 y 2001, GarciaHerrero y Santabárbara (2004) concluyeron que entre América Latina y China no hubo un efecto de sustitución de la afluencia de IED en perjuicio de la primera. Sin embargo, el estudio también pone de relieve que en los últimos años (1995-2001) el efecto China aumentó en forma significativa y que la afluencia de IED a ese país parece haber influido adversamente en las corrientes dirigidas a México y Colombia, en particular.

La información correspondiente al 2004 y el 2005 también es mixta. Indica que si bien China continúa disfrutando de una bonanza de IED, que ha alcanzado cifras superiores a los 60.000 millones de dólares, los países de América Latina se están recuperando de los niveles mínimos de la década del 2000. En el 2004, la inversión extranjera directa en Brasil aumentó un $80 \%$ y se elevó a más de 18.000 millones de dólares. En México también ha repuntado un $23 \%$, a 13.600 millones de dólares,

malicioso de uno de sus insecticidas patentados, sumándose al número cada vez mayor de inversionistas extranjeros que han debido recurrir a los tribunales para defender su propiedad intelectual. Además, la rentabilidad de las inversiones en China es discutible. Por ejemplo, en el último decenio los productores de cerveza extranjeros han invertido cientos de millones de dólares en China, en circunstancias de que, según The Economist (2005), estas inversiones tienen en promedio un escaso margen de utilidad: solo $0,5 \%$ en el caso de los 400 principales productores de cerveza que operan en China (incluidas las empresas mixtas extranjeras). Resulta interesante comparar esta información con lo que sucede en América Latina. De acuerdo con un estudio del China Economic Quarterly, en el 2001 las utilidades directas e indirectas del total de filiales estadounidenses que operan en China alcanzaron 2.800 millones de dólares, esto es, casi la mitad de los 4.400 millones de dólares que obtuvieron ese mismo año en México, con una población más de 10 veces menor. Según otra investigación empírica sobre el control político y los resultados de las empresas registradas en China, estos resultados se relacionan directamente con el poder decisorio de los comités locales del partido (respecto de los accionistas principales). Véase Chang y Wong (2003); véase también Wong, Opper y Hu (2004).

${ }^{39}$ Véanse análisis empíricos aplicados a América Latina en GarciaHerrero y Santabárbara (2004) y en Chantasasawat, Fung y otros, (2004); para otros análisis centrados en Asia, véase Eichengreen y Tong (2005a y 2005b), así como Mercereau (2005). 
mientras que en Chile aumentó 66\%, aproximándose a los 5.000 millones de dólares. Es posible que los años dorados de afluencia de IED hacia América Latina (el decenio de 1990) hayan terminado, al menos hasta que se reanude el proceso de privatizaciones.

Con todo, en lo que respecta a los flujos de capital, es posible que en el futuro las inversiones chinas en el exterior se conviertan en una bendición. China ya no es solamente receptor de IED, sino que ha dado un gran paso adelante en materia de inversiones en ultramar. En el período 1991-2003, estas ascendieron a cerca de 35.000 millones de dólares y en el 2003 se duplicaron con creces, elevándose a 2.000 millones de dólares (cifra que, pese a todo, sigue siendo baja). En los años siguientes esta tendencia se mantuvo. En el 2004, un $50 \%$ de la IED china se dirigió a América Latina (más que el 30\% destinado a Asia). En el 2005, las empresas transnacionales chinas invirtieron en el extranjero una cifra sin precedentes, cercana a los 7.000 millones de dólares. Aunque el grueso de esta suma se dirigió a Asia (60\%), América Latina continuó figurando como segundo receptor de la IED china ( $16 \%$ del total).

La necesidad de asegurar los recursos en alimentos y productos básicos está impulsando la IED a través de sociedades internacionales estratégicas. Las empresas chinas ya han realizado inversiones en sectores productivos de Angola, Argelia, Australia e Indonesia, y en África son inversionistas importantes, principalmente en los campos de la energía y las materias primas. De acuerdo con una encuesta realizada a 100 organismos de promoción de las inversiones dada a conocer por la UNCTAD, China ocupó el quinto lugar como inversionista en el exterior, después de Estados Unidos, Alemania, el Reino Unido y Francia. ${ }^{40}$ En el 2004, las empresas chinas multiplicaron los esfuerzos por aumentar sus inversiones en el extranjero no solo en otros países emergentes, sino también en países desarrollados. Así lo demuestran la adquisición por Lenovo de unidades de producción de la IBM (en 1.750 millones de dólares), y los intentos de empresas chinas como Minmetals de adquirir la canadiense Noranda, en 5.000 millones de dólares, o del conglomerado petrolero China National Off-shore Oil Corporation (CNOOC) de comprar la estadounidense Unocal, en más de 13.000 millones de dólares.

Como lo hicieron los japoneses hace algunos decenios, al parecer, las empresas chinas apuntan a ampliarse en el extranjero. Para América Latina, esto parece ser una buena oportunidad. No se trata solamente de que dos grandes

40 Véase UNCTAD, 2004. países asiáticos — Japón y China— muestren interés por la región, sino también de que ambos persiguen lo mismo, es decir, asegurarse un flujo continuo de materias primas y productos agrícolas y sus derivados. Para lograrlo, ambos necesitan que los países de América Latina cuenten con infraestructura confiable en materia de puertos, aeropuertos, carreteras y vías férreas. En consecuencia, a la región se le presenta una oportunidad única de participar en un nuevo juego de competencia. Además, esto le da la posibilidad de aplicar una estrategia industrial orientada a evitar que se profundice su especialización en el comercio de productos básicos y, como en el caso de Trinidad y Tabago, a fomentar la diversificación con industrias de mayor valor agregado que aprovechen su dotación de recursos naturales.

América Latina está en la mira de las empresas chinas. Hacia el 2001, China había creado más de 300 empresas en la región, con inversiones por más de 1.000 millones de dólares. Posteriormente, el principal fabricante chino de acero, Baosteel, realizó en Brasil la mayor inversión extranjera directa de la historia de China, ascendente a 1.500 millones de dólares. China también ha informado que piensa invertir 2.000 millones de dólares en la industria brasileña de aluminio, aunque los planes aún no se han materializado. Por otra parte, a través del grupo Shougang, China controla la principal mina de hierro peruana, posee intereses mayoritarios en un yacimiento petrolífero ecuatoriano y está intentando producir combustible y reactivar las minas de oro en la República Boliviarana de Venezuela. También se espera que China invierta en ferrocarriles y puertos de Brasil $y$, en general, en toda América Latina. El interés chino por mejorar la infraestructura es grande, con el fin de facilitar el transporte de los productos hasta los puertos. En Argentina, China se ha comprometido a invertir 25 millones de dólares en un puerto granelero y otros 250 millones en una carretera entre Argentina y Chile que facilitará la exportación de materias primas argentinas desde puertos chilenos.

Es probable que surjan acuerdos similares al suscrito en octubre de 2004 por Telefónica, principal empresa española autorizada para operar en América Latina, y Huawei, el gigante chino en equipos de telecomunicaciones. En virtud de este acuerdo Telefónica pone sus instalaciones a disposición de Huawei para que este ingrese al mercado regional y venda sus productos a las filiales que Telefónica tiene en América Latina. ${ }^{41}$ En el 2006, el

${ }^{41}$ Huawei es un claro ejemplo del proceso de internacionalización de las empresas chinas. Como parte de una ambiciosa estrategia de expansión a nivel mundial, esta empresa prevé aumentar sus ventas 
BBVA, importante banco español, aumentó su presencia en China mediante la apertura de oficinas en Shanghai y Beijing, y la reactivación de las operaciones de su sede de Hong Kong. Asimismo, suscribió un acuerdo con el Banco de China, principal banco del país, para captar las remesas chinas provenientes de Estados Unidos y de algunos países de América Latina, como Perú.

Las empresas de América Latina también están buscando oportunidades de negocios en China, como lo demostró la visita oficial realizada a este país en 2004 por el presidente Luiz Inácio Lula de Silva, acompañado de casi 400 empresarios brasileños. Algunas empresas importantes de la región ya se han instalado en Brasil, como es el caso de Embraer, fabricante brasileño de aviones, que vende y fabrica en China aviones de propulsión a chorro, ${ }^{42}$ o de Marcopolo, otra empresa brasileña, fabricante de chasis de autobuses, que piensa montar una planta en el país asiático. Ambas empresas continuaron el camino iniciado por Embraco, que fue el

internacionales desde 2.300 millones de dólares en el 2004 a más de 10.000 millones en el 2008. En el 2003, Huawei invirtió en el exterior $27 \%$ de los 4.000 millones de dólares de su inversión total, alcanzando mercados como Suecia y Noruega. Actualmente la empresa opera en más de 70 países y más de 3.000 de los 24.000 empleados del grupo trabajan en el extranjero. En el 2004, dos quintas partes de los 5.000 millones de dólares de utilidades provinieron de fuera de China (The Economist, 2005; Financial Times, 2005). Sin embargo, como lo subraya Yasheng Huang, del Massachusetts Institute of Technology (MIT), en la práctica la mayoría de los "ases chinos" son empresas extranjeras. Lenovo, que en 2004 adquirió el negocio de los computadores personales a IBM, es un ejemplo de ello. Técnicamente hablando es una empresa extranjera, ya que sus operaciones en China dependen de la oficina de Hong Kong. Las cuatro empresas chinas clasificadas por Forbes como las de mayor dinamismo tienen su sede en Hong Kong. Como bien señala Huang (2005), al parecer, el éxito de China no se debe tanto a que se hayan creado instituciones eficientes, sino a que se les ha dado libertad para escapar de las instituciones ineficientes. Véase también http://web.mit.edu/yshuang/www/ ${ }^{42}$ Véase un estudio al respecto en Goldstein (2004). primero en instalar una planta en Beijing en 1995. Diez años más tarde le siguió Weg, fabricante de motores, que montó en China la primera planta de propiedad íntegramente brasileña. A su vez, el fabricante de acero Gerday anunció la adquisición de una planta siderúrgica china, mientras que la empresa belga-brasileña Inbev adquirió una fábrica local de cerveza. No hay duda de que respecto al dinamismo de las corrientes comerciales, habría que examinar más a fondo el flujo de capitales entre China y América Latina e instar a que se realicen otros estudios que amplíen el alcance del presente trabajo.

Pero más allá de sus efectos en el comercio y las inversiones, es posible que China genere un tercer y último impacto: el efecto cognitivo. El desarrollo económico chino es muy pragmático. Su singular combinación de capitalismo y comunismo despierta creciente interés. Economistas destacados, como Ricardo Hausmann y Dani Rodrik, ya han hecho hincapié en la dimensión comercial de este inusual gigante emergente y en el hecho de que el milagro económico chino no radica solamente en el volumen que han alcanzado sus exportaciones, sino también, y por sobre todo, en la calidad cada vez mayor de ellas: lo que China exporta vale (Rodrik, 2006; Hausmann, Hwang y Rodrik, 2006). El pragmatismo económico de las autoridades chinas también está llamando la atención de responsables de formular políticas en todo el mundo. El milagro chino no es resultado de un proceso dirigido por un grupo de Chicago boys, ni producto de una misión Kemmerer. A China no llegaron asesores extranjeros ni gurús del desarrollo económico. Si Jeffrey Sachs asesoró a Bolivia, nunca llegó a China, al menos con sus consejos. La lección que se está desprendiendo del proceso chino es que no existe una fórmula mágica para el desarrollo, ni una clave mágica para concebir un paradigma singular que permita abrir las puertas al milagro del desarrollo. 
APÉNDICE A

Competencia comercial entre China y América Latina

CUADRO A.1

América Latina (quince países): promedio anual $\mathrm{Cl},{ }^{a}$ período $1998-2004^{b}$

\begin{tabular}{|c|c|c|c|c|c|c|c|}
\hline & 1998 & 1999 & 2000 & 2001 & 2002 & 2003 & 2004 \\
\hline México & 0,49 & 0,51 & 0,52 & 0,54 & 0,54 & 0,52 & 0,53 \\
\hline Costa Rica & 0,31 & 0,26 & 0,28 & 0,33 & 0,36 & 0,31 & 0,33 \\
\hline Brasil & 0,25 & 0,27 & 0,3 & 0,3 & 0,28 & 0,25 & 0,26 \\
\hline El Salvador & 0,21 & 0,23 & 0,23 & 0,27 & 0,26 & 0,24 & 0,26 \\
\hline Colombia & 0,19 & 0,16 & 0,19 & 0,21 & 0,19 & 0,18 & 0,18 \\
\hline Guatemala & 0,16 & 0,15 & 0,16 & 0,17 & 0,16 & 0,18 & 0,17 \\
\hline Argentina & 0,17 & 0,16 & 0,18 & 0,17 & 0,15 & 0,13 & 0,14 \\
\hline Perú & 0,17 & 0,16 & 0,17 & 0,17 & 0,15 & 0,13 & 0,13 \\
\hline Uruguay & 0,19 & 0,17 & 0,16 & 0,16 & 0,13 & 0,13 & 0,12 \\
\hline Chile & 0,11 & 0,11 & 0,11 & 0,11 & 0,1 & 0,09 & 0,09 \\
\hline Honduras & 0,11 & 0,15 & 0,12 & 0,14 & 0,12 & 0,09 & $\ldots$ \\
\hline Panamá & 0,12 & 0,11 & 0,11 & 0,11 & 0,1 & 0,08 & 0,08 \\
\hline Venezuela (Rep. Bol. de) & 0,11 & 0,08 & 0,09 & 0,08 & 0,07 & 0,06 & 0,06 \\
\hline Paraguay & 0,07 & 0,07 & 0,08 & 0,07 & 0,06 & 0,05 & 0,05 \\
\hline
\end{tabular}

Fuente: elaboración propia.

a El promedio CI es el promedio aritmético entre el coeficiente de especialización y el coeficiente de conformidad.

b Según orden descendente de la columna relativa al año 2004.

CUADRO A.2

China y 10 países de América Latina: índice de especialización de Balassa

\begin{tabular}{|c|c|c|c|c|c|c|c|c|c|c|c|}
\hline & China & México & Costa Rica & Brasil & El Salvador & Colombia & Guatemala & Argentina & Perú & Chile & $\begin{array}{c}\text { Venezuela } \\
\text { (Rep. Bol. de) }\end{array}$ \\
\hline Productos de madera & 0,43 & 0,26 & 0,51 & 2,26 & 2,99 & 0,78 & 0,91 & 0,60 & 0,58 & 4,10 & $\ldots$ \\
\hline Productos de cuero & 3,34 & $\ldots$ & 0,60 & 2,88 & 1,40 & 0,93 & 0,66 & 1,98 & - & - & $\ldots$ \\
\hline Productos químicos & 0,42 & 0,34 & 0,75 & 0,62 & 1,16 & 0,86 & 1,44 & 0,68 & 0,35 & 0,62 & 0,29 \\
\hline Alimentos elaborados & 0,47 & 0,56 & 2,11 & 2,93 & 5,17 & 1,49 & 4,73 & 6,60 & 4,13 & 2,53 & 0,16 \\
\hline Minerales & 0,28 & 1,06 & $\ldots$ & $\mathbf{1 , 0 5}$ & 0,54 & 3,63 & 0,76 & 1,75 & 2,56 & 1,67 & 7,54 \\
\hline Manufacturas básicas & 0,96 & 0,69 & 0,44 & 1,60 & 1,39 & 1,04 & 0,77 & 0,75 & 2,86 & 3,66 & 1,09 \\
\hline Maquinaria no electrónica & 0,52 & 0,84 & 0,10 & 0,82 & 0,11 & 0,09 & 0,12 & 0,22 & 0,06 & 0,07 & 0,05 \\
\hline Alimentos frescos & 0,68 & 0,80 & 5,67 & 4,13 & 3,00 & 4,14 & 7,18 & $\mathbf{5 , 5 0}$ & 2,52 & 4,54 & 0,11 \\
\hline Manufacturas varias & 1,48 & 1,07 & 1,39 & 0,27 & 0,92 & 0,44 & 0,51 & 0,20 & 0,35 & 0,11 & 0,05 \\
\hline Prendas de vestir & 3,46 & 1,29 & 1,51 & 0,12 & 1,93 & 1,48 & 1,14 & $\ldots$ & 2,81 & $\ldots$ & $\ldots$ \\
\hline Componentes electrónicos & 1,04 & 1,53 & $\cdots$ & 0,20 & 0,24 & 0,12 & 0,20 & 0,05 & $\ldots$ & $\ldots$ & $\ldots$ \\
\hline $\begin{array}{l}\text { Tecnologías de la } \\
\text { Información y arts. de } \\
\text { consumo electrónicos }\end{array}$ & 2,43 & 1,75 & 2,40 & 0,26 & $\ldots$ & $\cdots$ & $\ldots$ & $\ldots$ & $\ldots$ & $\ldots$ & $\ldots$ \\
\hline
\end{tabular}

Fuente: elaboración propia a partir de la base de datos Intracen 2004, de UNCTAD/OMC. 
APÉNDICE B

\section{Cargos por manipulación de contenedores}

\begin{tabular}{|c|c|c|c|c|c|c|c|c|c|c|}
\hline \multirow[t]{2}{*}{ País } & \multirow{2}{*}{$\begin{array}{l}\text { Índice de } \\
\text { restricción } \\
\text { de mani- } \\
\text { pulación } \\
\text { de carga }\end{array}$} & \multirow{2}{*}{$\begin{array}{l}\text { Índice de } \\
\text { servicios } \\
\text { obligatorios }\end{array}$} & \multirow{2}{*}{$\begin{array}{l}\text { Índice de } \\
\text { acuerdos } \\
\text { de fijación } \\
\text { de precios }\end{array}$} & \multirow{2}{*}{$\begin{array}{l}\text { Índice de } \\
\text { acuerdos } \\
\text { de coope- } \\
\text { ración }\end{array}$} & \multirow{2}{*}{$\begin{array}{c}\text { Plazo } \\
\text { medio de } \\
\text { desadua- } \\
\text { namiento } \\
\text { (días) }\end{array}$} & \multirow{2}{*}{$\begin{array}{c}\text { Índice de } \\
\text { eficiencia } \\
\text { portuaria } \\
(1-7)\end{array}$} & \multirow{2}{*}{$\begin{array}{l}\text { Índice de } \\
\text { criminalidad } \\
\quad(1-7)\end{array}$} & \multicolumn{3}{|c|}{$\begin{array}{l}\text { Cargos por manipulación de } \\
\text { contenedores }\end{array}$} \\
\hline & & & & & & & & $\begin{array}{c}\text { Índice del } \\
\text { Banco } \\
\text { Mundial }^{\mathrm{a}}\end{array}$ & $\begin{array}{l}\text { Índice } \\
\mathrm{CMPCH}^{\mathrm{b}}\end{array}$ & $\begin{array}{l}\text { Índice } \\
\text { LSU }^{\mathrm{c}}\end{array}$ \\
\hline Singapur & 1 & 0,38 & 0 & 0,33 & 2 & 6,76 & 6,72 & 117 & $\ldots$ & $\ldots$ \\
\hline Hong Kong & 0 & 0,25 & 0 & 0 & $\ldots$ & 6,38 & 5,46 & $\ldots$ & $\ldots$ & $\ldots$ \\
\hline Taiwán & 0,5 & 0 & 0 & 0 & $\ldots$ & 5,18 & 4,49 & 140 & 163 & $\ldots$ \\
\hline Japón & 0,75 & 0,13 & 0,89 & 1 & $\ldots$ & 5,16 & 5,16 & 250 & 202 & $\ldots$ \\
\hline Malasia & 0 & 0,25 & 0 & 0,38 & 7 & 4,95 & 5,76 & 75 & $\ldots$ & $\ldots$ \\
\hline España & 0 & 0,06 & 1 & 0 & 4 & 4,88 & 6,08 & 200 & 105 & $\ldots$ \\
\hline Corea & 0 & 0,38 & 0 & 0 & $\ldots$ & 4,12 & 5,22 & $\ldots$ & $\ldots$ & $\ldots$ \\
\hline Tailandia & 0,5 & 0,63 & 0 & 0,38 & 4 & 3,98 & 5,12 & 93 & $\ldots$ & $\ldots$ \\
\hline Argentina & 0 & 0,13 & 0 & 1 & 7 & 3,81 & 4,52 & $\ldots$ & 139 & $\ldots$ \\
\hline Vietnam & 0 & 0 & 0 & 0,50 & $\ldots$ & 3,81 & 5,02 & $\ldots$ & $\ldots$ & $\ldots$ \\
\hline Chile & 0 & 0,25 & 0,43 & 1 & 3 & 3,76 & 6,05 & 202 & 100 & $\ldots$ \\
\hline China & 0,5 & 0 & 0 & 0 & 7 & 3,49 & 4,44 & 110 & $\ldots$ & $\ldots$ \\
\hline Indonesia & 1 & 0,06 & 0 & 0,38 & 5 & 3,41 & 4,06 & $\ldots$ & $\ldots$ & $\ldots$ \\
\hline México & 0,5 & 0,38 & 0 & 1 & 4 & 3,34 & 2,61 & $\ldots$ & $\ldots$ & $\ldots$ \\
\hline \multicolumn{11}{|l|}{ Venezuela } \\
\hline (Rep. Bol. de) & 0 & 0 & 1 & 1 & 11 & 3,28 & 3,63 & $\ldots$ & $\ldots$ & $\ldots$ \\
\hline El Salvador & 0 & 0 & 0 & 1 & 4 & 2,95 & 2,3 & $\ldots$ & $\cdots$ & 61 \\
\hline Brasil & 0,5 & 0,75 & 0 & 1 & 10 & 2,92 & 4,45 & 328 & 292 & $\cdots$ \\
\hline Perú & 0,5 & 0 & 0,5 & 1 & 7 & 2,88 & 3,32 & $\ldots$ & 142 & $\cdots$ \\
\hline India & 0 & 0 & 0 & 1 & $\ldots$ & 2,79 & 4,28 & $\ldots$ & $\ldots$ & $\ldots$ \\
\hline Filipinas & 0,5 & 0 & 0 & 0,38 & 7 & 2,79 & 3,51 & 118 & $\ldots$ & $\ldots$ \\
\hline Ecuador & 0 & 0 & 0,43 & 1 & 15 & 2,63 & 3,65 & $\ldots$ & 139 & $\ldots$ \\
\hline Costa Rica & 0 & 0 & 0 & 1 & 4 & 2,46 & 3,28 & $\cdots$ & $\ldots$ & 68 \\
\hline Colombia & 0,5 & 0,13 & 0,5 & 1 & 7 & 2,26 & 1,88 & $\ldots$ & $\ldots$ & $\ldots$ \\
\hline Bolivia & $\ldots$ & $\ldots$ & $\ldots$ & $\ldots$ & 9,5 & 1,61 & 4,38 & $\cdots$ & $\cdots$ & $\cdots$ \\
\hline Uruguay & 0 & 0 & 0 & 1 & 5 & $\ldots$ & $\ldots$ & $\ldots$ & $\cdots$ & $\ldots$ \\
\hline
\end{tabular}

Fuente: Clark, Dollar y Micco (2004).

a Dólares por TEU (feet equivalent unit).

b $\mathrm{CMPCH}=$ Cámara Marítima Portuaria de Chile.

c Índice lsu del National Ports and Waterways Institute, de los Estados Unidos.

(Traducido del inglés) 
Bibliografía

Ahearne, A., J. Fernald y otros (2003): China and Emerging Asia: Comrades or Competitors?, International Finance Discussion Paper, $\mathrm{N}^{\circ} 789$, Washington, D.C., Board of Governors of the Federal Reserve System, diciembre.

América Economía (2003): El ataque del dragón, 26 de diciembre. Disponible en www.americaeconomia.com

Anderson, J. y E. van Wincoop (2003): Gravity with gravitas: a solution to the border puzzle, American Economic Review, vol. 93, $\mathrm{N}^{\circ}$ 1, Nashville, Tennessee, American Economic Association.

(2004): Trade costs, Journal of Economic Literature, vol. 42, $\mathrm{N}^{\circ} 3$, Nashville, Tennessee, American Economic Association, septiembre. Disponible en http://fmwww.bc.edu/ ec-p/wp593.pdf

Banco de España (2004): Where is the Chinese Banking Sector Going? Banking Reform in the People's Republic of China, Madrid, abril, inédito.

BBVA (Banco Bilbao Vizcaya Argentaria) (2003): México y China en el comercio mundial, Latinwatch, junio.

(2004): Potencial económico de China y oportunidades para Argentina, Latinwatch, abril.

Berges, R. (2004): Implications of eventual changes to China's peg, Latin America Investment Strategy Implications, Nueva York, Merrill Lynch.

Berthelon, M. y C. Freund (2003): On the conservation of distance in international trade, Washington, D.C., Universidad de Maryland/Banco Mundial, noviembre, inédito.

BID (Banco Interamericano de Desarrollo) (2004): The emergence of China: opportunities and challenges for Latin America and the Caribbean, documento preparado para la conferencia "The emergence of China: opportunities and challenges for Latin America and the Caribbean" (Washington, D.C., 1 de octubre de 2004), Washington, D.C.

(2006): The Emergence of China: Opportunities and Challenges for Latin America and the Caribbean, Washington, D.C., Banco Interamericano de Desarrollo/Rockefeller Center.

Brun, J.F., C. Carrère y otros (2005): Has distance died? Evidence from a gravity model, World Bank Economic Review, vol. 19, $\mathrm{N}^{\mathrm{o}}$ 1, Washington, D.C., Banco Mundial.

CAF (Corporación Andina de Fomento) (2006): América latina en el comercio global. Ganando mercados, Caracas.

Carrère, C. y M. Schiff (2003): On the geography of trade: distance is alive and well, Université d'Auvergne/Banco Mundial, diciembre, inédito. Disponible en http://team.univ-paris1. fr/teamperso/disdier/meta.pdf

CEPAL (Comisión Económica para América Latina y el Caribe) (2004a): Los efectos de la adhesión de China a la OMC en las relaciones económicas con América Latina y el Caribe, Panorama de la inserción internacional de América Latina y el Caribe, 20022003, LC/G.2221-P, Santiago de Chile. Publicación de las Naciones Unidas, $\mathrm{N}^{\mathrm{o}}$ de venta: S.04.II.G.45.

(2004b): La inversión extranjera en América Latina y el Caribe, 2003, LC/G.2226-P, Santiago de Chile. Publicación de las Naciones Unidas, $N^{\circ}$ de venta: S.04.II.G.54.

(2005): Aspectos estratégicos de la relación entre China y América Latina y el Caribe, Panorama de la inserción internacional de América Latina y el Caribe, 2004. Tendencias 2005, LC/G.2283-P, Santiago de Chile.
Clark, X., D. Dollar y A. Micco (2004): Port efficiency, maritime transport costs and bilateral trade, Journal of Development Economics, vol. 75, № 2, Amsterdam, Elsevier, diciembre.

Chang, E. y S. Wong (2003): Political control and performance in China's listed companies, Hong Kong, Universidad de Hong Kong, marzo, inédito.

Chantasasawat, B., K.C. Fung y otros (2004): Foreign Direct Investment in East Asia and Latin America: Is there a People's Republic of China Effect?, ADBI Discussion Paper, № 17, Manila, Banco Asiático de Desarrollo.

Chu, T. y T. Prusa (2004): The Reasons for and the Impact of Antidumping Protection: The Case of People's Republic of China, East-West Center Working Papers, $N^{\circ} 69$, Honolulu, East West Center. Disponible en http://www.eastwestcenter.org/stored/ pdfs/ECONwp069.pdf

De Paiva de Abreu, M. (2005): China's emergence in the global economy and Brazil, textos para discussão, $N^{\circ} 491$, Río de Janeiro, Departamento de Economía, Pontificia Universidad Católica de Río de Janeiro, inédito.

Deardoff, A. De Paiva (2004): Local Comparative Advantage: Trade Costs and the Pattern of Trade, Discussion Paper, No 500, Michigan, University of Michigan Gerald Ford School of Public Policy, febrero. Disponible en http://www.fordschool.umich. edu/rsie/workingpapers/Papers476-500/r500.pdf

Deutsche Bank (2004): China's Financial Sector: Institutional Framework and Main Challenges, Frankfurt, enero.

Disdier, A.C. y K. Head (2004): Exaggerated Reports of the Death of Distance: Lessons from a Meta-Analysis, París, Université de Paris I Panthéon Sorbonne/University of British Columbia, febrero, inédito. Disponible en http://team.univ-paris1.fr/teamperso/disdier/meta.pdf

Eichengreen, B. (2004): Chinese Currency Controversies, CEPR Discussion Paper, $\mathrm{N}^{\circ} 4375$, Londres, Centre for Economic Policy Research, mayo.

(2006): China's exchange rate regime: the long and short of it, marzo, Departamento de Economía, Universidad de California en Berkeley, inédito.

Eichengreen, B. y H. Tong (2005a): How China is reorganizing the world economy, Berkeley, Departamento de Economía, Universidad de California en Berkeley/ Bank of England, diciembre, inédito.

(2005b): Is China's FDI Coming at the Expense of other Countries?, NBER Working Paper, Nº 11335, Cambridge, Massachusetts, National Bureau of Economic Research.

Eichengreen, B., Y. Rhee y H. Tong (2004): The Impact of China on the Exports of other Asian Countries, NBER Working Paper, $\mathrm{N}^{\mathrm{o}} 10768$, Cambridge, Massachusetts, National Bureau of Economic Research, septiembre.

Evans, C. y J. Harrigan (2003): Distance, Time, and Specialization, NBER Working Paper, $N^{\circ}$ 9729, Cambridge, Massachusetts, National Bureau of Economic Research. Disponible en http://www.ny.frb. org/research/economists/harrigan/papers.html

Financial Times (2005): The challenge from China: why Huawei is making the telecoms world take notice, 11 de enero.

FMI (Fondo Monetario Internacional) (2004): The global implications of the US fiscal deficit and of China's growth, World Economic Outlook, Washington, D.C., abril.

Garcia-Herrero, A. y D. Santabárbara (2004): Does China have an impact on Foreign Direct Investment to Latin America?, docu- 
mento de trabajo presentado en la First LAEBA Conference on the Challenges and Opportunities of the Emergence of China (Beijing), Banco de España.

Gaulier, L. y D. Ünal-Kesenci (2005): China's Integration in East Asia: Production Sharing, FDI \& High-Tech Trade, París, Centre d'études prospectives et d'informations internationales, junio.

Glaeser, E. y J. Kohlhase (2003): Cities, Regions and the Decline of Transportation Costs, Discussion Paper, No 2014, Harvard, Harvard Institute of Economic Research, julio. Disponible en http://post.economics.harvard.edu/hier/2003papers/ HIER2014.pdf

Goldman Sachs (2005): How Solid are the BRICS?, Goldman Sachs Global Economics Paper, No 134 , Nueva York.

Goldstein, A. (2004): A Latin American global player goes to Asia: Embraer in China, París, Centro de Desarrollo de la Organización de Cooperación y Desarrollo Económicos (OCDE), inédito.

Golsdtein, A., N. Pinaud y otros (2006): The Rise of China and India: What's in it for Africa?, París, Centro de Desarrollo de la OCDE.

Harrigan, J. y A. Venables (2004): Timeliness, Trade and Agglomeration, NBER Working Paper, № 10404, Cambridge, Massachusetts, National Bureau of Economic Research, marzo.

Hausmann, R., J. Hwang y D. Rodrik (2006): What you export matters, Harvard, Harvard University/John F. Kennedy School of Government/Department of Economics, marzo, inédito.

Heston, A. y R. Summers (1997): PPPs and Price Parities in Benchmark Studies and the Penn World Table, CICUP 971, documento presentado en la Conferencia de la Oficina de Estadística de las Comunidades Europeas (EUROSTAT) (Bélgica).

HSBC (Hong-Kong Shanghai Bank Corporation) (2005): Wild Geese Flying, Londres, HSBC Global Research, diciembre.

Huang, Y. (2003): Selling China, Cambridge, Massachusetts, Cambridge University Press.

(2005): China's big hope is not Hong-Kong, Financial Times, 14 de enero.

Hummels, D. (2001a): Toward a geography of trade costs, West Lafayette, Indiana, Purdue University, Krannert School of Management, septiembre, inédito. Disponible en http://www. mgmt.purdue.edu/faculty/hummelsd/

(2001b): Time as a trade barrier, West Lafayette, Indiana, Purdue University, Krannert School of Management, julio, inédito. Disponible en http://www.mgmt.purdue.edu/faculty/hummelsd/

Ianchovichina, E. y W. Martin (2001): Trade Liberalization in China's Accession to the World Trade Organization, Policy Research Working Paper, No 2623, Washington, D.C., Banco Mundial.

(2003): Economic Impacts of China's Accession to the World Trade Organization, Policy Research Working Paper, № 3053 , Washington, D.C., Banco Mundial.

Ianchovichina, E. y T. Walmsley (2003): Impact of China's WTO Accession on East Asia, Policy Research Working Paper, № 3109 , Washington, D.C., Banco Mundial.

Lall, S. y J. Weiss (2004): People's Republic of China Competitive Threat to Latin America: an Analysis for 1990-2002, Discussion Paper, $\mathrm{N}^{\mathrm{o}} 14$, Tokio, Asian Development Bank Institute, octubre, inédito.

LatinFocus (2004): febrero.
Limao, N. y A.J. Venables (2000): Infrastructure, geographical disadvantage and transport costs, The World Bank Economic Review, vol. 15, No 3, Washington, D.C., Banco Mundial.

Lin, J.Y. (2004): The People's Republic of China future development and economic relations with Latin America, Tokyo, Asian Development Bank Institute, noviembre, inédito.

Lora, E. (2004a): ¿Es posible competir con la China? Fortalezas y debilidades de China respecto a América Latina, Washington, D.C., Departamento de Investigación, Banco Interamericano de Desarrollo, abril, inédito.

(2004b): Can Latin America compete with China? Washington, D.C., Departamento de Investigación, Banco Interamericano de Desarrollo, abril, presentación en power point.

Maddison, A. (1998): Chinese Economic Performance in the Long Run, París, Centro de Desarrollo de la Organización de Cooperación y Desarrollo Económicos (OCDE).

McKibbin, W. y W. Thye Woo (2003): The consequences of China's WTO accession for its neighbours, Asian Economic Papers, vol. 2, $\mathrm{N}^{\circ}$ 2, Cambridge, Massachusetts, The MIT Press.

Mercereau, B. (2005): FDI Flows to Asia: Did the Dragon Crowd out the Tigers?, Working Paper, $\mathrm{N}^{\circ} 189$, Washington, D.C., Fondo Monetario Internacional.

Rodrik, D. (2006): What's so special about China's exports?, Harvard, Harvard University, John F. Kennedy School of Government, inédito.

Rumbaugh, T. y N. Blancher (2004): China: International Trade and WTO Accession, Working Paper WP/04/36, Washington, D.C., Fondo Monetario Internacional, marzo.

Shiue, C. y W. Keller (2004a): Markets in China and Europe in the Eve of the Industrial Revolution, NBER Working Paper, $\mathrm{N}^{\mathrm{o}} 10778$, Cambridge, Massachusetts, National Bureau of Economic Research.

(2004b): Market Integration and Economic Development: a Long-run Comparison, NBER Working Paper, No 10300, Cambridge, Massachusetts, National Bureau of Economic Research, febrero.

Shixue, J. (2004): Sino-Latin America economic relations and China's perspective on Latin American economy, Beijing, Institute of Latin American Studies/Chinese Academy of Social Sciences, inédito.

Soler, J. (2003): Impacto sobre los flujos comerciales entre China y el mundo, en J. Soler (comp.), El despertar de la nueva China. Implicaciones del ingreso de China en la Organización Mundial del Comercio, Madrid, Catarata.

The Economist (2005): Special report: China's champions, Londres, 8 de enero.

The Wall Street Journal (2004): Challenges from China spur Mexican factories to elevate aspirations, 5 de marzo.

UNCTAD (Conferencia de las Naciones Unidas sobre Comercio y Desarrollo) (2004): Prospects for FDI flows, transnational corporations strategies and promotion policies: 2004-2007. Global investment prospects assessment (GIPA) research note 1: results of a survey of location experts, $\mathrm{TD}(\mathrm{XI}) / \mathrm{BP} / 5$, Ginebra, abril.

Wilson, D. y R. Purushothaman (2003): Dreaming with BRICs: the Path to 2050, Global Economics Paper, $\mathrm{N}^{\circ}$ 99, octubre.

Wong, S., S. Opper y R. Hu (2004): Shareholding structure, depoliticization, and firm performance: lessons from China's listed firms, Economics of Transition, vol. 12, № 1, Oxford, Reino Unido, Blackwell Publishing. 
Xiao, G. (2005): Round-tripping Foreign Direct Investment in the People's Republic of China: Scale, Causes, and Implications, ADBI Policy Research Brief, $N^{\circ} 10$, Manila, Banco Asiático de Desarrollo.

Yang, Y. (2003): China's Integration into the World Economy: Implications for Developing Countries, Working Paper WP/03/245, Washington, D.C., Fondo Monetario Internacional.

Yao, Y., F. Li y otros (2003): Goldman Sachs' China challenges, Norwegian School of Economics MIB Paper, Bergen, inédito.

Young, A. (2000): The razor's edge: distortions and incremental reform in the People's Republic of China, Quarterly Journal of Economics, vol. 115, $\mathrm{N}^{\circ}$ 4, Cambridge, Massachusetts, The MIT Press, noviembre.

(2003): Gold into base metals: productivity growth in the People's Republic of China during the reform period, Journal of Political Economy, vol. 111, No 6, Chicago, The University of Chicago Press, diciembre.

Zijian Wang, S. y J. Wei (2004): Structural Change, Capital's Contribution, and Economic Efficiency: Sources of China's Economic Growth between 1952-1998, documento de trabajo, Göteborg, Göteborg University, inédito. 